Aus der Klinik für Thorax-, Herz und Gefäßchirurgie

(Prof. Dr. med. I. Kutschka)

der Medizinischen Fakultät der Universität Göttingen

\title{
Impact of cerebral protection strategy used during open surgical aortic arch replacement on visceral function
}

\author{
INAUGURAL-DISSERTATION \\ zur Erlangung des Doktorgrades \\ der Medizinischen Fakultät der \\ Georg-August-Universität zu Göttingen
}

vorgelegt von

Saddam Mohammed Ahmed Al-Sabri

aus

Sana'a/Jemen

Göttingen 2019 
Dekan:

\section{Betreuungsausschuss}

Betreuer/in

Ko-Betreuer/in:

\section{Prüfungskommission}

Referent/in

Ko-Referent/in:

Drittreferent/in:

Datum der mündlichen Prüfung:
Prof. Dr. rer. nat. H. K. Kroemer

Prof. Dr. med. A. Bräuer

Prof. Dr. med. B. Danner

Prof. Dr. med. A. Bräuer

Prof. Dr. med. M. Oppermann

07.04.2020 
Hiermit erkläre ich, die Dissertation mit dem Titel „Impact of cerebral protection strategy used during open surgical aortic arch replacement on visceral function" eigenständig angefertigt und keine anderen als die von mir angegebenen Quellen und Hilfsmittel verwendet zu haben.

Göttingen, den 


\section{Content}

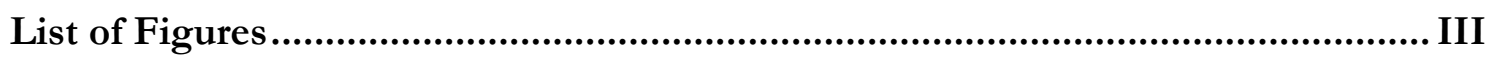

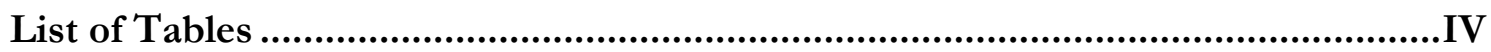

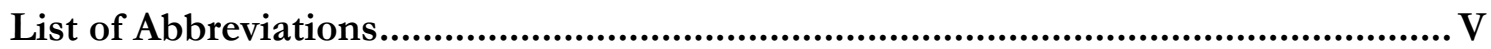

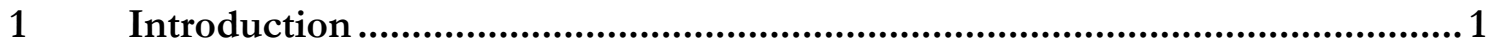

1.1 Open Surgical Aortic Arch Replacement.................................................................................. 1

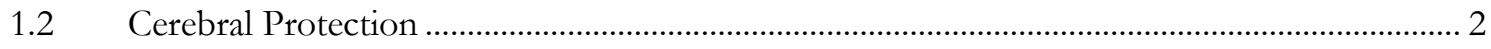

$1.3 \quad$ Visceral Malperfusion ........................................................................................................ 4

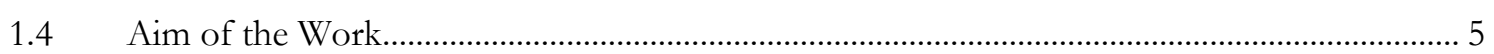

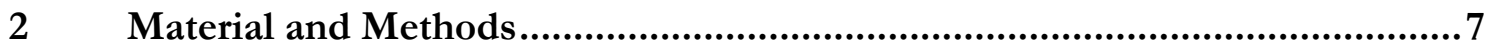

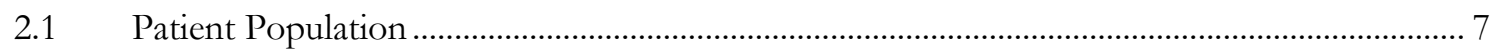

2.2 Anesthetic Protocol and Medication ………………......................................................... 7

2.3 Surgical Procedure and Type of Cerebral Protection .................................................................... 8

2.3.1 Deep Hypothermic Circulatory Arrest.............................................................................. 8

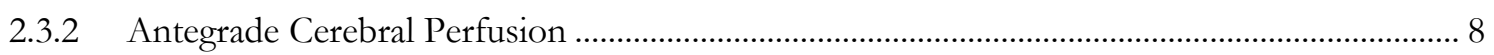

2.3.3 Retrograde Cerebral Perfusion ............................................................................................... 9

$2.4 \quad$ Data Collection Protocol......................................................................................................... 9

2.5 Pre-operative Clinical and Demographic Data ........................................................................ 10

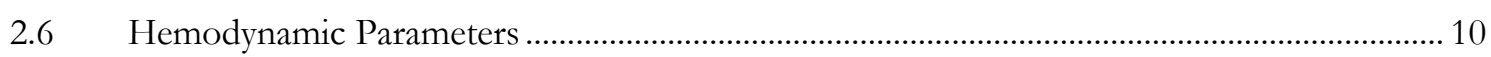

2.7 Cathecolamine-, Transfusion- and Coagulation Therapy....................................................... 10

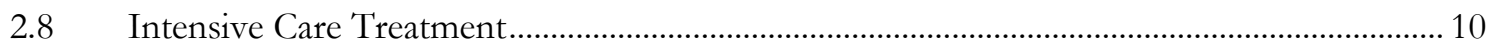

2.9 Blood Gas Analysis and Abdominal Biomarkers .................................................................. 10

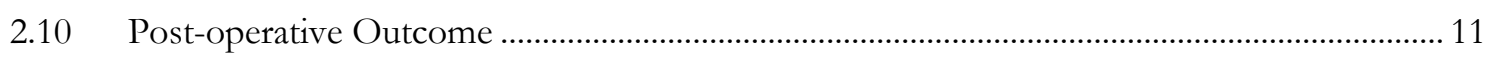

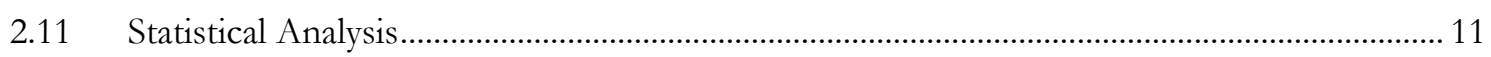

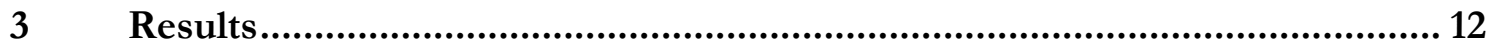

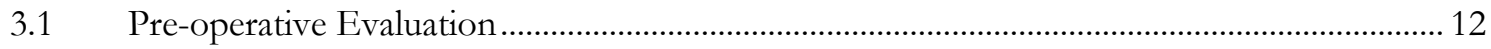

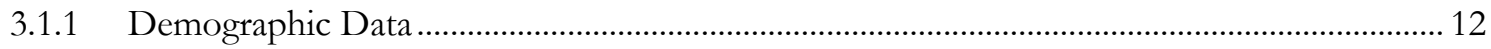

3.1.2 Clinical and Imaging Characteristics of the Aortic Disease ……………................................. 12

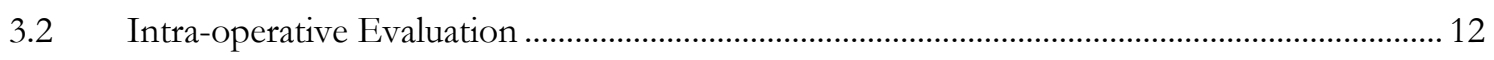

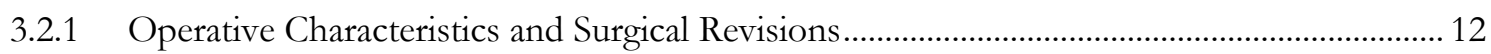

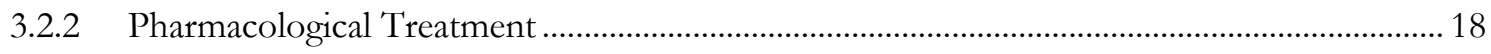

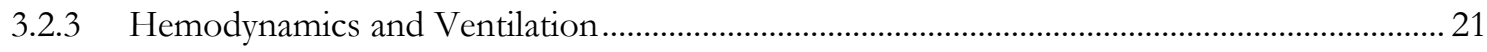

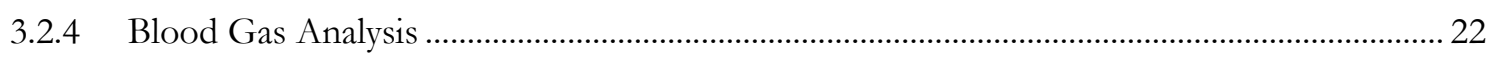

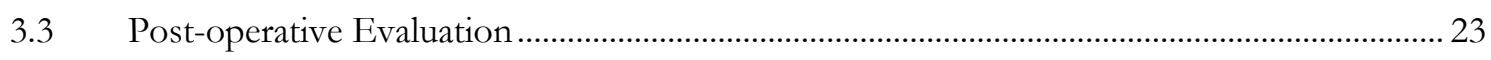

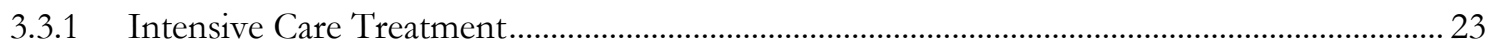




\begin{tabular}{|c|c|}
\hline 3.3 .2 & Hemodynamic Monitoring \\
\hline 3.3 .3 & Pharmacologic Treatment .......... \\
\hline 3.4 & Laboratory Analysis of Abdominal Markers .............................. \\
\hline 3.5 & Duration of Post-operative Care \\
\hline 3.6 & Mortality ...................... \\
\hline 3.7 & 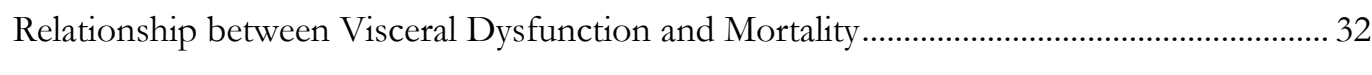 \\
\hline 4 & 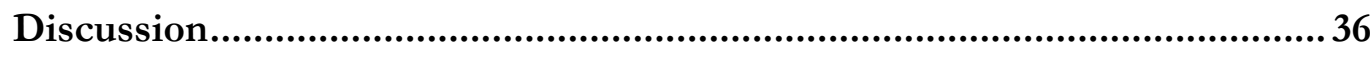 \\
\hline 4.1 & Limitations ................................................................... \\
\hline 4.2 & 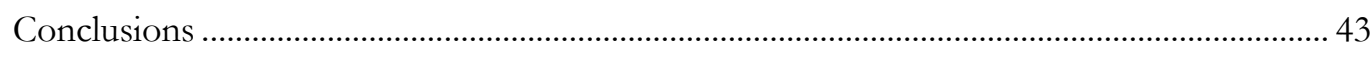 \\
\hline 5 & 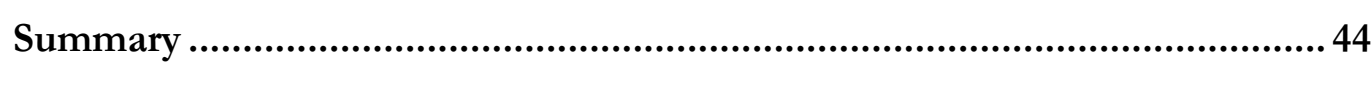 \\
\hline 5.1 & Zusammenfassung - Summary in German ............. \\
\hline 6 & References..... \\
\hline
\end{tabular}




\section{List of Figures}

Figure 1: Effect of additional cardiac and/or aortic root operation on the operative times .............. 17

Figure 2: Proportion of patients requiring intra-operative cathecolamines and buffer..................... 18

Figure 3: Intra-operative application of cathecolamines and buffer................................................. 19

Figure 4: Proportion of patients requiring intra-operative blood replacement therapy ..................... 20

Figure 5: Intra-operative administration of blood products ................................................................ 20

Figure 6: Post-operative arterial lactate values in the subgroups (at the end of the operation) ......... 21

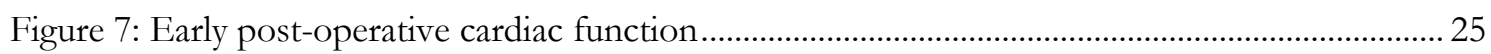

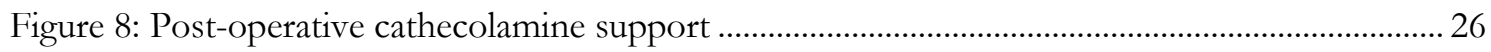

Figure 9: Incidence of post-operative blood replacement therapy (ICU) ........................................2 27

Figure 10: Magnitude of post-operative blood replacement therapy (ICU) ........................................2 27

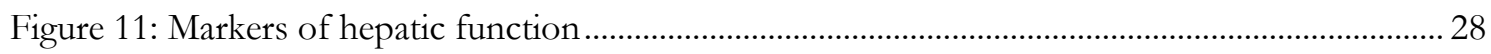

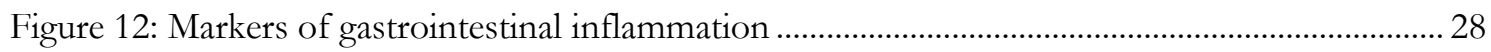

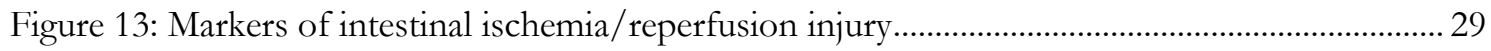

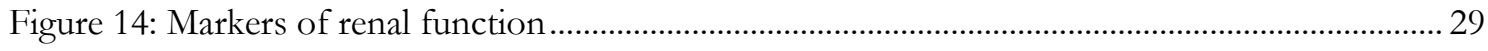

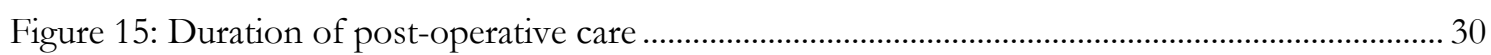

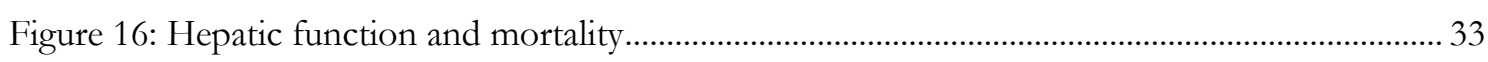

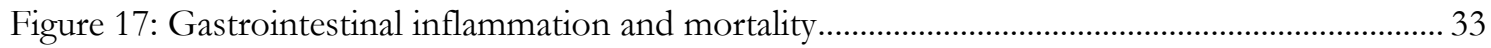

Figure 18: Intestinal ischemia/reperfusion damage and mortality .................................................. 34

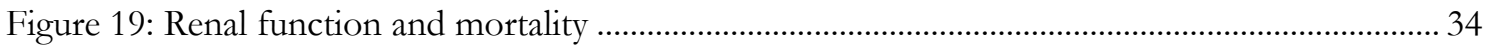

Figure 20: Relationship between pre-operative lactate values and mortality....................................... 35 


\section{List of Tables}

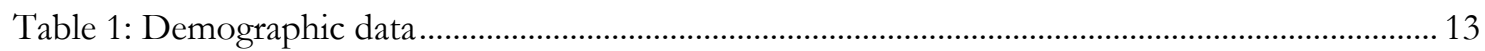

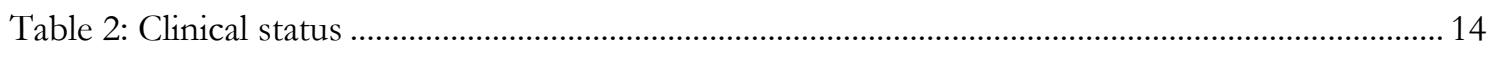

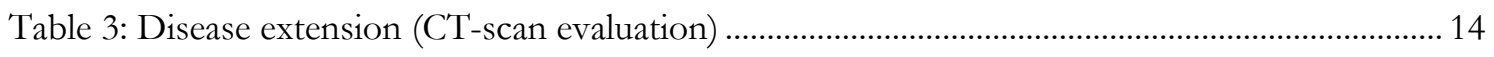

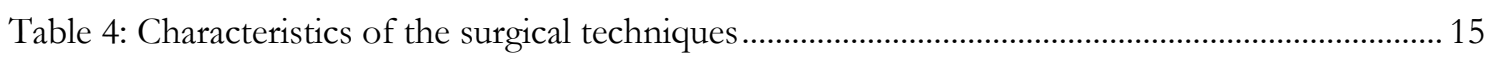

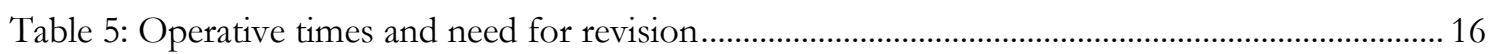

Table 6: Post-operative hemodynamics and ventilation (at the end of the operation) ......................... 21

Table 7: Pre-operative blood gas analysis (at the beginning of the operation) ...................................... 22

Table 8: Post-operative blood gas analysis (at the end of the operation) ............................................... 23

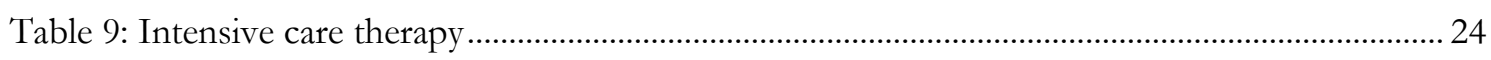

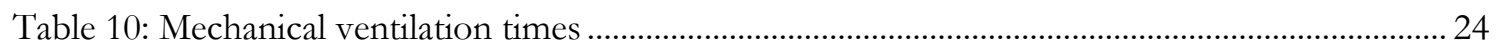

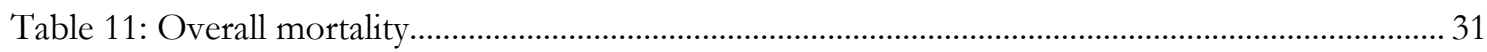

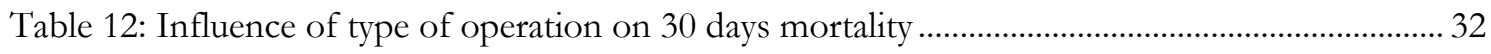




\section{List of Abbreviations}

\begin{tabular}{|c|c|}
\hline$\beta$ & probability of type II error \\
\hline AB therapy & antibiotic therapy \\
\hline $\mathrm{ACP}$ & antegrade cerebral perfusion \\
\hline add OP & additional operation \\
\hline ANOVA & analysis of variance \\
\hline Ao. rupture & aortic rupture \\
\hline AP & alcalic phosphatase \\
\hline Arch Rep & arch replacement \\
\hline Art. hypertension & arterial hypertension \\
\hline Asc. aorta & ascending aorta \\
\hline ATP & adenosine triphosphate \\
\hline AUC & area under the curve \\
\hline AVR & aortic valve replacement \\
\hline BMI & body mass index \\
\hline BUN & blood urea nitrogen \\
\hline DHCA & deep hypothermic circulatory arrest \\
\hline CABG & coronary artery bypass surgery \\
\hline CK & creatine kinase \\
\hline COPD & chronic obstructive pulmonary disease \\
\hline $\mathrm{CPB}$ & cardiopulmonary bypass \\
\hline Crea & creatinine \\
\hline FET & frozen elephant trunk \\
\hline $\mathrm{FiO}_{2}$ & fraction of inspired oxygen \\
\hline FPP & fresh frozen plasma \\
\hline
\end{tabular}




\begin{tabular}{|c|c|}
\hline GGT & gamma-glutamyltranspeptidase \\
\hline GPT & glutamate-pyruvate transaminase \\
\hline $\mathrm{H}^{+}$ & hydrogen ion \\
\hline $\mathrm{Hb}$ & hemoglobin \\
\hline $\mathrm{H}_{2} \mathrm{CO}_{3}$ & hydrogen bicarbonate \\
\hline CI & cardiac index \\
\hline Htc & hematocrit \\
\hline $\mathrm{CO}$ & cardiac output \\
\hline ICU & intensive care unit \\
\hline Intra-OP & intra-operative \\
\hline $\mathrm{K}^{+}$ & potassium ion \\
\hline LOS & length of stay \\
\hline Lower E. Neurology & lower extremity neurology \\
\hline LV-EF & left ventricular ejection fraction \\
\hline $\mathrm{N}$ & number of patients \\
\hline $\mathrm{Na}^{+}$ & sodium ion \\
\hline $\mathrm{NaBic}$ & sodium bicarbonate \\
\hline NAG & $\mathrm{N}$-acetyl- $\beta$-d-glucosaminidase \\
\hline NIRS & near-infrared spectroscopy \\
\hline $\mathrm{p}$ & $\mathrm{p}$-value \\
\hline PC & platelet concentrate \\
\hline $\mathrm{pCO}_{2}$ & partial pressure of carbon dioxide \\
\hline PEEP & positive end-expiratory pressure \\
\hline Perf. & perfusion \\
\hline P insp & pressure inspiratory \\
\hline PICCO & pulse contour cardiac output \\
\hline
\end{tabular}




\begin{tabular}{|l|l|}
\hline PO2 & partial pressure of oxygen \\
\hline POD & post-operative day \\
\hline post-OP & post-operative \\
\hline PPSB & prothrombin complex concentrate \\
\hline PRBC & packed red blood cells \\
\hline Pre-OP & pre-operative \\
\hline Prev. Sternotomy & previous sternotomy \\
\hline RCP & retrograde cerebral perfusion \\
\hline RR sys & systolic blood pressure \\
\hline RR diast & diastolic blood pressure \\
\hline SaO2 & oxygen saturation \\
\hline SCP & selective cerebral perfusion \\
\hline SD & standard deviation \\
\hline SEM & standard error of the mean \\
\hline SPSS & tratistical Package for the Social Sciences, (SPSS Inc., Chicago) \\
\hline T & upper extremity neurology \\
\hline Upper E. Neurology & \\
\hline
\end{tabular}




\section{Introduction}

Ascending and transverse aortic arch aneurysms represent the great majority of aortic pathology (Lemole 1995) and are usually repaired through median sternotomy and under a short period of circulatory arrest. Numerous and diverse techniques of aortic arch replacement have been previously described (Bachet et al. 1991; Borst et al. 1988; Danner et al. 2007; Griepp et al. 1975; Kazui et al. 2001; Kouchoukos et al. 2001); and they depend on the morphologic characteristics of the disease on one side and of the personal preferences of the surgical team, the local clinical habits and experience on the other side.

All techniques include the performance of three anastomoses: a proximal anastomosis to the ascending aorta, a distal anastomosis to the descending aorta and the arch anastomosis (singular or multiple) to the supra-aortic vessels.

\subsection{Open Surgical Aortic Arch Replacement}

The "traditional method" for total aortic arch replacement, that was described by Griepp (Griepp et al. 1975) and popularized by Crawford and others (Crawford and Saleh 1981; Svensson et al. 1993) as the "distal aortic anastomosis first" technique, encompasses execution of the distal anastomosis and aortic arch anastomoses during the hypothermic circulatory arrest interval. The "elephant trunk" technique allows performance of secondstage descending aortic operations in case of disease progression such as an evolving aneurysm or chronic dissection (Schepens et al. 2002; Kieffer et al. 2000). The hybrid techniques - called "frozen elephant trunk" for Type A acute aortic dissection - in which the "elephant trunk" is replaced by a stent-graft deployed in the proximal descending aorta or in the distal arch could improve difficult repairs and broaden the indications for highrisk patients (Kato et al. 1996; Karck et al. 2003). The traditional "distal anastomosis first" technique still represents the gold standard associated with excellent outcomes (Bachet 2008).

However, the "arch first" technique including performance of the anastomosis between the graft and the brachiocephalic arteries first is thought to minimize the period of brain ischemia. This technique provides arterial brain perfusion without requiring direct cannulation and perfusion of the brachiocephalic arteries (that could potentially result in embolization and stroke) (Kouchoukos et al. 2001). 
Total replacement with "the proximal-first" technique is usually performed through a median sternotomy. The technique also allows immediate proximal repair during the cardiac arrest and the cooling period. In addition, antegrade cerebral perfusion can be immediately initiated and arch reconstruction performed before circulatory arrest. The circulatory arrest time is significantly reduced and needed only for the performance of the distal aortic anastomosis. Besides reducing both, myocardial ischemia and cerebral perfusion time (Tominaga et al. 2002), "the proximal-first" technique is simpler to perform and associated with fewer complications (Tominaga 2008). This technique should be considered for total aortic arch replacement, especially when extensive aortic root reconstruction is necessary.

\subsection{Cerebral Protection}

Adequate cerebral protection during aortic arch surgery is considered crucial for outcome. Continuous brain perfusion have succeeded in decreasing the incidence of neurological complications (Tchervenkov et al. 2001; Pigula et al. 2000), however organ and system injury due to lack of perfusion below the aortic arch remains unclear. Whereas peripheral malperfusion was reported to contribute to poor prognosis after surgical aortic arch repair (Chiu and Miller 2016), visceral malperfusion caused by direct occlusion or circulatory arrest was shown to independently increase the risk for early and late mortality (Patel et al. 2008). Exposure to cardiopulmonary bypass, temperature changes and whole body ischemia/reperfusion may also trigger perturbations in the homeostatic, inflammatory and oxidative stress pathways that may further result in systemic inflammatory response syndrome and its progression to multiorgan failure. Sustained metabolic debt and multiorgan failure may contribute to post-operative morbidity and mortality after aortic arch surgery despite the progressive surgical techniques and improved neurological monitoring. Deeper hypothermia during circulatory arrest (Griepp et al. 1975), perfusion of the left subclavian artery, drainage of spinal fluid (Matsumura et al. 2009) and the use of a stent-graft matching the patients' anatomy, could secondarily prevent visceral malperfusion by preservation of collateral circulation.

The optimal brain protection technique during total replacement of aortic arch has not been clearly established. The objective of all current cerebral protection methods is prevention of cellular anoxia and acidosis and reduction of the energy requirements to the minimum necessary to maintain cellular viability in order to maintain the integrity of the central nervous system while the cerebral blood flow is interrupted. Deep hypothermia, 
antegrade cerebral perfusion and retrograde cerebral perfusion are established tools of cerebral protection during circulatory arrest.

Initially, it has been emphasized that deep hypothermia alone could adequately protect the brain and viscera during brief periods of circulatory arrest, thus, enabling aortic replacement without perfusion (Urbanski et al. 2012). Indeed, deep hypothermic circulatory arrest (DHCA) reduces metabolic demands and oxygen consumption of the brain and the viscera and thus increases tolerance to hypoxia (Lewis and Taufic 1953; Elefteriades 2010). However, the DHCA technique provides only a restricted time to the surgeon to finish the aortic repair (Lai et al. 2002). It was shown that a $18^{\circ} \mathrm{C}$ core temperature may theoretically allow a safe DHCA for 45 to 60 minutes, but prolonged DHCA times exceeding this limit would increase the incidence of adverse neurologic outcome (Moon and Sundt 2002a; Svensson et al. 1993). However, complex arch pathology may require longer periods of safe arrest then that provided by DHCA only.

Retrograde cerebral perfusion (RCP) through the superior vena cava was first described in 1980 by Mills and Ochsner (Mills and Ochsner 1980), as a tool for the "emergency treatment for massive air embolism during cardiopulmonary bypass (CPB)". Later Lemole et al. (1982), (Lemole 1995; Bavaria et al. 2001) reported RCP as a cerebral protective technique during the surgical repair of aortic dissections. RCP could reduce the ischemic damage caused by DHCA alone (Bonser and Harrington 2008) and induce a beneficial washout of toxic ischemia-related excitatory amino acids and metabolites (Baumgartner et al. 1997; Tseng et al. 1999). While most of the studies focused on determining the neurologic effects of the technique, little is known about the impact of RCP on abdominal viscera.

Antegrade cerebral perfusion (ACP) pioneered by Kazui and Bachet (Kazui 2001; Bachet et al. 1991), in which the brain is selectively perfused through the right axillary or subclavian artery or by direct carotid and brachiocephalic cannulation, has been wildey used for elective aortic arch procedures (Okita et al. 2001; Strauch et al. 2004). ACP is physiologically superior to DHCA with or without RCP because it supplies sufficient oxygenated blood to the brain, thus maintaining the physiological brain energy metabolism (Sakurada et al. 1996). Several clinical studies have shown improved results regarding survival and neurologic outcomes using ACP compared to historical reference data (Kazui et al. 2001; Sanioglu et al. 2008; Etz et al. 2008). Moreover, ACP significantly reduced postoperative length of stay (LOS) in the ICU accompanied with less renal dysfunction and improved survival when compared with DHCA (Di Eusanio et al. 2003). Algra et al. 
(2012a) suggested that a partial perfusion of the viscera through collaterals during ACP (Andropoulos et al. 2003; Ly et al. 2011; Miyaji et al. 2010; Pigula et al. 2001) may be responsible for the improved outcome. Evidence of regional blood flow has been also reported in the abdominal or femoral arteries during ACP (Andropoulos et al. 2003; Ly et al. 2011; Pigula et al. 2001). However, the eventual protective effect of ACP on abdominal organ function remains speculative.

\subsection{Visceral Malperfusion}

Malperfusion of the abdominal organs is known to be a devastating complication of type A aortic dissection per se. Approximately one-third of acute Stanford type-A aortic dissection patients manifest pre-operative malperfusion syndrome (Bonser et al. 2011; Immer et al. 2006; Geirsson et al. 2007; Girdauskas et al. 2009) of various organ systems, and it is wellknown that end-organ malperfusion has the potential to dramatically decrease the chance of successful outcome. Pacini et al. (2013) reported a $2.4 \%$ incidence of mesenteric malperfusion and found an associated hospital mortality as high as 70\%. Whereas visceral malperfusion associated with acute aortic dissection has an incidence of 3\%-5\%, patients with intestinal ischemia have an operative mortality rate ranging from $43 \%$ to $87 \%$ (Fann et al. 1990; Apaydin et al. 2002). In consent, multivariate analysis also confirmed mesenteric malperfusion to be an independent risk factor for mortality (Pacini et al. 2013). Whereas single-organ malperfusion is associated with a mortality rate of $34.7 \%$, two organ system involvement increases mortality up to $61.9 \%$. In the presence of three or more organ system malperfusion the mortality rate was reported to rise to $85.7 \%$ (Pacini et al. 2013).

The real effect of various perfusion strategies on cerebral protection and operative mortality has not yet been clearly outlined (Goldstein et al. 2001; Moon and Sundt 2002b; Ehrlich et al. 2000; Hagl et al. 2001). Several studies (Oudemans-van Straaten et al. 1996; Tsunooka et al. 2006; Dong et al. 2009) revealed the susceptibility of the intestine to microcirculatory perfusion in the setting of cardiac surgery, showing an association with intestinal barrier dysfunction, bacterial translocation and neutrophil infiltration.

Organ-specific biomarkers are able to estimate the degree of visceral injury at an early postoperative time point (Zierer et al. 2007; Andrási et al. 2014). Neutrophil gelatinaseassociated lipocalin is the most widely described marker for renal injury; however, kidney injury molecule-1, liver fatty acid binding protein, intestinal fatty acid binding protein, glutathione s-transferase and $N$-acetyl- $\beta$-D-glucosaminidase have been also reported 
(Thuijls et al. 2011; Derikx et al. 2007; Liang et al. 2010; Krawczeski et al. 2011; Askenazi et al. 2011; Du et al. 2011). However, in the emergency life-saving non-elective setting of dissection, the realization of a prospective study for the establishment of new laboratory markers remains difficult. Moreover, in cases where pre-operative damage is present the relative change of these markers is difficult to be interpreted. Nevertheless, renal biomarkers (Liang et al. 2010; Krawczeski et al. 2011; Askenazi et al. 2011; Du et al. 2011; Waikar et al. 2010) confirmed that DHCA results in more renal injury than ACP.

More recent studies (Algra et al. 2012a; Algra et al. 2012b) suggest that ACP might provide more abdominal perfusion than does DHCA via the collateral circulation granted by the perfusion of the left subclavian arteries. Consequently, this seems to have a protective effect on the viscera.

\subsection{Aim of the Work}

To date, there is no consensus among surgeons dealing with large volumes of aortic arch pathologies on the best visceral protection strategy.

It remains further unclear whether post-operative visceral malperfusion is depending on and consequently might be influenced by the intra-operative perfusion management or rather remains a hallmark of the pre-operative status.

The clinical effects of current methods of brain protection (DHCA, RCP and ACP) on the post-operative visceral function in conditions of pre-operatively present malperfusion remained unexplored.

The purpose of the current investigation is:

1) to determine how different approaches of cerebral protection used at our institution during the last two decades influenced operative mortality, clinical outcome and long-term survival after open surgical aortic arch replacement;

2) to establish relationships to visceral organ dysfunction;

3) to report on the influence of type of disease, type of procedures and the role of additional procedures on the post-operative visceral dysfunction;

4) to evaluate the effect of pre-operative visceral ischemia on the post-operative development of malperfusion syndrome; 
5) to identify biochemical markers and analyze clinical outcome that would support the theory of improved visceral protection offered by the use of antegrade selective cerebral perfusion. 


\section{$2 \quad$ Material and Methods}

Retrospectively, data was collected by medical chart review from all consecutive adult patients who underwent aortic arch replacement with the use of deep hypothermic circulatory arrest between June 2005 and March 2016 at the Department of Thoracic, Cardiac and Vascular Surgery, University Medical Center of Göttingen, Germany. An institutional ethics review board's approval was obtained for the collection and analysis of the data in a retrospective fashion (No. 2-10-17). The need for informed consent was waived.

\subsection{Patient Population}

Between June 2005 and March 2016, 128 consecutive adult patients with acquired aortic arch disease underwent for the first time open surgical aortic arch replacement under circulatory arrest at the Department of Thoracic, Cardiac and Vascular Surgery, University of Göttingen, Germany. Patients with congenital diseases or requiring repeated aortic arch replacement were excluded from the present study. The patients were retrospectively divided into 3 main groups according to whether they did have deep hypothermic circulatory arrest without additional cerebral perfusion (DHCA), did have selective antegrade cerebral perfusion (ACP) or did have retrograde cerebral perfusion (RCP). DHCA was applied in 37 patients, ACP in 70 patients and RCP in 21 patients.

\subsection{Anesthetic Protocol and Medication}

Before anesthesia and surgery antihypertensive therapy with beta-blockers was applied first, before other vasodilators, if necessary. Right radial arterial pressure monitoring was instituted before induction of anesthesia.

Anesthesia was induced by sufentanil, followed by a hypnotic (mostly midazolam or etomidate) and muscle relaxation was provided with pancuronium or rocuronium. During the procedure anesthesia was maintained with sufentanil and a volatile anesthetic - mostly sevoflurane.

The alpha-stat method was used to carry out $\mathrm{pH}$ balance control in all patients. Aprotinin administration was rare. Arterial pressure was usually measured on the left radial artery. Regional oxygen saturation in the bilateral frontal lobes with near-infrared spectroscopy 
was usually used for cerebral monitoring. Pharmacologic neuroprotection was not performed.

Blood pressure deviations were corrected with norepinephrine and nitroglycerine in both groups. In order to maintain an adequate perfusion pressure and cardiac output, mean arterial pressure was held between $60 \mathrm{mmHg}$ and $70 \mathrm{mmHg}$ by administration of volume, and optimization of heart rate and rhythm. Inotropic support was started with dobutamine or epinephrine. Blood sampling was routinely performed and registered during the operations.

\subsection{Surgical Procedure and Type of Cerebral Protection}

All patients underwent median sternotomy. Cardiopulmonary bypass (CPB) was instituted after heparinisation. The arterial cannula was placed in the ascending aorta or the femoral artery and a venous single 2 -stage cannula in the right atrium. Left ventricular venting was always perfomed through a vent placed through the right superior pulmonary vein. Myocardial protection was achieved with cold crystalloid cardioplegia and topical pericardial cooling (Di Eusanio et al. 2002).

After completion of the aortic procedure, warming was carried out by means of CPB until a rectal temperature of $35^{\circ} \mathrm{C}$ was achieved, limiting the gradient between $\mathrm{CPB}$ blood and body temperature to less than $10^{\circ} \mathrm{C}$, and a maximal warming temperature of $37^{\circ} \mathrm{C}$. (Reich et al. 1999).

\subsubsection{Deep Hypothermic Circulatory Arrest}

Profound hypothermia was achieved by cooling on CPB. During the cooling period of 30 to 40 minutes, the proximal aortic anastomosis was usually performed. When a core temperature of $18^{\circ} \mathrm{C}$ was achieved, circulation was arrested and the distal repair was carried out. The head was packed in ice to prevent warming of the central nervous system.

\subsubsection{Antegrade Cerebral Perfusion}

The cannulation techniques during ACP with moderate hypothermic circulatory include arterial cannulation through the subclavian artery with or without femoral cannulation (Di Eusanio et al. 2002; Dossche et al. 2000). Cooling is performed on CPB to achieve a core temperature of $18^{\circ} \mathrm{C}$ to $22^{\circ} \mathrm{C}$, then the systemic circulation can be arrested and the aneurysm opened. Cerebral perfusion cannulas were then inserted into the innominate and 
left common carotid arteries through the aortic lumen, while the patient was positioned in the Trendelenburg position and connected to the oxygenator with a separate single-roller pump head. The left subclavian artery may be clamped or occluded to avoid the steal phenomenon. Cerebral perfusion was adjusted to maintain a right radial arterial pressure between 40 and $70 \mathrm{~mm} \mathrm{Hg}$ as described by Di Eusanio et al. (2002). Circulatory arrest was instituted during the open performance of the distal anastomosis.

\subsubsection{Retrograde Cerebral Perfusion}

RCP was applied through an arteriovenous shunt to a superior vena cava cannula (28F to 32F) after bicaval cannulation as described by Zierer et al. (2007). RCP was initiated at 100 $\mathrm{mL} / \mathrm{min}$ and increased to 300 to $500 \mathrm{~mL} / \mathrm{min}$. The innominate vein pressure (central venous pressure) was kept below 20 to $25 \mathrm{~mm} \mathrm{Hg}$. Dark blood was verified emanating from the brachiocephalic orifices in all patients. The temperature of inflow blood during RCP was $10^{\circ} \mathrm{C}$ (Zierer et al. 2007).

\subsection{Data Collection Protocol}

Demographic and clinical data have been collected from the medical charts. Operative and ischemic times as well as type of the operations and their extension have been collected from the surgical operation chart. Pre-operative and post-operative hemodynamic data, ventilation parameters, data obtained from arterial blood gas analyses and intra-operative catecholamine support, as well as intra-operative transfusion and pharmacologic optimization of coagulopathy were also quantified. Hemodynamic and ventilatory parameters, arterial and venous blood gas analysis, catecholamine support, laboratory visceral markers, extent of the post-operative pharmacologic and mechanical support as well as renal replacement therapy and the need for surgical revision were extracted from the intensive care therapy and stationary evaluation charts.

Hemodynamic instability was defined as a state where the circulatory system is not able to provide adequate perfusion of the tissues due to hypovolemic, distributive, cardiogenic or obstructive factors (Sevransky 2009). Patients requiring fluid and inotropic resuscitation to maintain mean arterial blood pressure above $65 \mathrm{mmHg}$ are considered hemodynamically instable (Sevransky 2009). 


\subsection{Pre-operative Clinical and Demographic Data}

The following demographic and clinical data were collected pre-operatively: age, gender, risk factors (body mass index, hypertension, diabetes mellitus, smoking, ejection fraction, chronic obstructive pulmonary disease (COPD), renal replacement therapy and renal dysfunction), renal function variables (serum creatinine, serum urea, estimated creatinine clearance and hematocrit), urgency of surgery, associated surgical procedures (such as coronary artery bypass grafting, valve surgery, combined aortic root procedures).

\subsection{Hemodynamic Parameters}

Systolic and diastolic systemic as well as central venous pressure were registered intra- and post-operatively. Cardiac output monitoring was provided in high-risk catecholaminedependent patients during the intensive care stay.

\subsection{Catecholamine-, Transfusion- and Coagulation Therapy}

The following values were collected during the operation and during the post-operative period from the medical charts: inotropic substitution (epinephrine, norepinephrine, dopamine, dobutamine, enoximone; transfusion of red blood cell (PRBC), fresh frozen plasma (FFP), platelet (PC); substitution of prothrombin complex concentrate usage (PPSB) and fibrinogen; and buffering with NaBic and TRIS.

Inotrope scores were calculated using the following formula $\left(\mu \mathrm{g} \cdot \mathrm{kg}^{-1} \cdot \mathrm{min}^{-1}\right)$ : dopamine + dobutamine $+(15 \times$ enoximone $)+(100 \times$ epinephrine $)+(100 \times$ norepinephrine $)$ (Chen et al. 2006).

\subsection{Intensive Care Treatment}

Duration of mechanical ventilation, requirements and duration of renal replacement therapy, catecholamine support, buffer substitution and $\mathrm{AB}$ therapy were quantified during the ICU stay.

\subsection{Blood Gas Analysis and Abdominal Biomarkers}

Values of Hemoglobin ( $\mathrm{Hb}), \mathrm{PO}_{2}, \mathrm{PCO}_{2}, \mathrm{SO}_{2}, \mathrm{H}_{2} \mathrm{CO}_{3}, \mathrm{pH}$, lactate and electrolytes measured in the arterial blood with a Blood Gas Analyzer before and after the operation and during the intensive care stay were extracted from the charts. 
Hepatocellular injury was evaluated through GPT and GGT. Gastrointestinal damage was evaluated through alkaline phosphatase, bilirubin, lactate and creatine kinase levels. Renal function was evaluated by creatinine and blood urea nitrogen.

\subsection{Post-operative Outcome}

To further characterize post-operative outcomes, length of ICU stay, hospital stay and inhospital death were extracted. Intra-operative mortality, 48h mortality, 30 days mortality and in-hospital mortality were determined to evaluate the influence of type of circulatory support and establish potential interactions with abdominal organ function.

\subsection{Statistical Analysis}

Continuous variables are expressed as mean \pm standard error of the mean (mean \pm SEM). Student $t$-test for independent samples was used followed by Fisher exact test when needed. Categorical variables are presented as number (\%). In univariate analysis, categorical data was analyzed by square or Fisher exact tests and continuous data were analyzed by using t-test or Wilcoxon rank sum tests, as appropriate (Hong et al. 2017). Changes in parameter over the time were tested using repeated measures analysis of variance (ANOVA) followed by paired Student $t$-test. Differences among corresponding parameters of the three treatment groups were compared using one-way ANOVA. The power of a test was defined as $1-\beta$, where $B$ represented the probability of a type II error. A test is considered significant when the probability of type II error $\beta$ is less than 0.20 and thus, the power of the test higher than $80 \%$. The statistical analysis was performed using SPSS version 10.0 software (SPSS Inc., Chicago, IL). A two-tailed $P$-value of less than 0.05 was considered statistically significant. 


\section{Results}

\subsection{Pre-operative Evaluation}

\subsubsection{Demographic Data}

There were no significant differences between the three groups of patients in term of demographics, risk factors, heart function and previous heart surgery (Table 1).

\subsubsection{Clinical and Imaging Characteristics of the Aortic Disease}

With respect to the clinical presentation, patients suffered mainly from thoracic pain and the majority of them was hemodynamically stable (Table 2) in all three groups. Interestingly, pre-operative abdominal pain was not assessed in any of these patients. This finding could be explained by the fact that no complete occlusion of all three visceral arteries was present on the pre-operative CT-scan in none of the cases. More than $70 \%$ of the patients in each group were suffering from acute dissection involving the aortic arch, however, rarely showing true lumen collaps at abdominal level $(29.7 \%, 33.3 \%)$. No other significant differences in terms of disease extension were assessed between the groups (Table 3).

\subsection{Intra-operative Evaluation}

\subsubsection{Operative Characteristics and Surgical Revisions}

Whereas venous cannulations sites were similar between groups, subclavian artery cannulation was mostly used in the antegrade perfusion group (Table 4). Total arch replacement was almost always performed in the retrograde perfusion group, but only in the $60 \%$ of the cases operated without selective cerebral perfusion. Total arch replacement was almost always performed in the RCP group (95.2\%, p = 0.026 vs. ACP and DHCA); but in less percent in the DHCA (64.9\%) and ACP (74.3\%) groups; however, without significant differences between the DHCA and ACP groups. 
Table 1. Demographic data

\begin{tabular}{lcccc} 
& DHCA & ACP & RCP & P-value \\
\cline { 2 - 5 } Nr. of Patients & 37 & 70 & 21 & \\
\hline
\end{tabular}

$\begin{array}{lcccc}\text { Age (Mean } \pm \text { SD) } & 63.6 \pm 11.9 & 61.3 \pm 11.4 & 61.4 \pm 10.6 & 0.902 \\ \text { BMI (Mean } \pm \text { SD) } & 28.3 \pm 4.4 & 27.1 \pm 4.4 & 26.9 \pm 5.3 & 0.837 \\ \text { Male Gender }(\%) & 67.6 & 62.9 & 76.2 & 0.525 \\ \text { Art. Hypertension (\%) } & 83.8 & 87.1 & 80.9 & 0.759 \\ \text { Smoking (\%) } & 16.2 & 17.1 & 23.8 & 0.738 \\ \text { Diabetes mellitus (\%) } & 13.5 & 12.9 & 14.3 & 1.0 \\ \text { Renal Disease (\%) } & 21.6 & 24.3 & 9.5 & 0.385 \\ \text { COPD (\%) } & 8.1 & 7.1 & 9.5 & 0.905 \\ \text { LV-EF (Mean } \pm \text { SD of \%) } & 54.7 \pm 11.9 & 51.9 \pm 74.2 & 48.3 \pm 14.5 & 0.739\end{array}$

Prev. Sternotomy (\%)

Valve Surgery

CABG

Aortic Surgery
5.4

2.7

2.7
10.0

4.3

1.4
9.5

0.687

0.0

1.0

4.8

0.577

Legends for Table 1, Table 2, Table 3, Table 4: DHCA, circulatory arrest; ACP, antegrade cerebral perfusion, RCP, retrograde cerebral perfusion; BMI = body mass index; art. Hypertension, arterial hypertension; COPD $=$ chronic obstructive pulmonary disease; LV-EF = left ventricular ejection fraction; prev. Sternotomy, previous sternotomy; $\mathrm{CABG}=$ coronary artery bypass surgery, Pericard. Effusion (T), pericardial effusion (Tamponade); contained Ao. Rupture, contained aortic rupture; Asc. Aorta, ascending aorta; Replac., replacement; AVR, aortic valve replacement. $\mathrm{P}<0.05$ is statistically significant. 
Table 2. Clinical status

\begin{tabular}{lllllllll}
\hline & \multicolumn{2}{c}{ DHCA } & ACP & & RCP & P-value \\
\cline { 2 - 8 } Nr. of Patients & 37 & $\%$ & 70 & $\%$ & 21 & $\%$ & \\
\hline
\end{tabular}

$\underline{\text { Symptoms }}$

$\begin{array}{lccccccc}\text { Thoracic Pain } & 16 & \mathbf{4 3 . 2} & 39 & \mathbf{5 5 . 7} & 11 & \mathbf{5 2 . 4} & 0.453 \\ \text { Cerebral Neurology } & 4 & \mathbf{1 0 . 8} & 11 & \mathbf{1 5 . 7} & 3 & \mathbf{1 4 . 3} & 0.886 \\ \text { Upper E. Neurology } & 0 & \mathbf{0 . 0} & 1 & \mathbf{1 . 4} & 1 & \mathbf{4 . 8} & 0.384 \\ \text { Lower E. Neurology } & 2 & \mathbf{5 . 4} & 11 & \mathbf{1 5 . 7} & 1 & \mathbf{4 . 8} & 0.242\end{array}$

$\underline{\text { Hemodynamics }}$

$\begin{array}{lccccccc}\text { Post-Resuscitation } & 1 & \mathbf{2 . 7} & 4 & \mathbf{5 . 7} & 2 & \mathbf{9 . 5} & 0.504 \\ \text { Stable } & 34 & \mathbf{9 1 . 9} & 59 & \mathbf{8 4 . 3} & 16 & \mathbf{7 6 . 2} & 0.261 \\ \text { Unstable } & 3 & \mathbf{8 . 1} & 11 & \mathbf{1 5 . 7} & 5 & \mathbf{2 3 . 8} & 0.261\end{array}$

Table 3. Disease extension (CT-scan evaluation)

\begin{tabular}{lccccccc}
\hline & \multicolumn{2}{c}{ DHCA } & \multicolumn{2}{c}{ ACP } & \multicolumn{2}{c}{ RCP } & P-value \\
\cline { 2 - 7 } Nr. of Patients & 37 & $\%$ & 70 & $\%$ & 21 & $\%$ & \\
\hline Arch Aneurysm & 7 & $\mathbf{1 8 . 9}$ & 23 & $\mathbf{3 2 . 9}$ & 7 & $\mathbf{3 3 . 3}$ & 0.294 \\
Aortic Dissection & & & & & & & \\
\multicolumn{1}{c}{ Ascending } & 29 & $\mathbf{7 8 . 4}$ & 50 & $\mathbf{7 1 . 4}$ & 16 & $\mathbf{7 6 . 2}$ & 0.759 \\
$\quad$ Arch & 31 & $\mathbf{8 3 . 8}$ & 52 & $\mathbf{7 4 . 3}$ & 16 & $\mathbf{7 6 . 2}$ & 0.545 \\
$\quad$ Thoracic extension & 18 & $\mathbf{4 8 . 7}$ & 35 & $\mathbf{5 0 . 0}$ & 9 & $\mathbf{4 2 . 9}$ & 0.859 \\
\multicolumn{1}{c}{ Abdominal extension } & 11 & $\mathbf{2 9 . 7}$ & 22 & $\mathbf{3 1 . 4}$ & 7 & $\mathbf{3 3 . 3}$ & 0.966 \\
& & & & & & & \\
\hline Intramural Hematoma & 0 & $\mathbf{0 . 0}$ & 7 & $\mathbf{1 0 . 0}$ & 0 & $\mathbf{0 . 0}$ & 0.066 \\
Pericard. Effusion (T) & 11 & $\mathbf{2 9 . 7}$ & 19 & $\mathbf{2 7 . 1}$ & 7 & $\mathbf{3 3 . 3}$ & 0.833 \\
Contained Ao. Rupture & 2 & $\mathbf{5 . 4}$ & 8 & $\mathbf{1 1 . 4}$ & 1 & $\mathbf{4 . 8}$ & 0.619 \\
Free Aortic Rupture & 0 & $\mathbf{0 . 0}$ & 2 & $\mathbf{2 . 9}$ & 0 & $\mathbf{0 . 0}$ & 0.681 \\
& & & & & & & \\
\hline
\end{tabular}


Whereas the Yacoub procedure was applied in 19\% of the RCP cases and was rarely used in the ACP cases, the Bentall procedure was the most preferred procedure for root repair and was additionally performed in approximately $30 \%$ of the cases of each group.

Aortic valve reconstruction and coronary revascularization was similarly performed in all groups (Table 4).

Table 4. Characteristics of the surgical techniques

\begin{tabular}{lllllllll}
\hline & \multicolumn{3}{c}{ DHCA } & \multicolumn{2}{c}{ ACP } & & RCP & P-value \\
\cline { 2 - 8 } Nr. of Patients & 37 & $\%$ & 70 & $\%$ & 21 & $\%$ & \\
\hline
\end{tabular}

Cannulation

\begin{tabular}{lccccccc} 
Asc. Aorta & 9 & $\mathbf{2 4 . 3}$ & 18 & $\mathbf{2 5 . 7}$ & 4 & $\mathbf{1 9 . 1}$ & 0.885 \\
Femoral Artery & 28 & $\mathbf{7 5 . 7}$ & 32 & $\mathbf{4 5 . 7}$ & 16 & $\mathbf{7 6 . 2}$ & $\mathbf{0 . 0 0 2}$ \\
Subclavian Artery & 0 & $\mathbf{0 . 0}$ & 20 & $\mathbf{2 8 . 6}$ & 1 & $\mathbf{4 . 8}$ & $\mathbf{0 . 0 0 0 0 6}$ \\
Right Atrium & 34 & $\mathbf{9 1 . 9}$ & $\mathbf{6 7}$ & $\mathbf{9 5 . 7}$ & 20 & $\mathbf{9 5 . 7}$ & 0.764 \\
Femoral Vein & 3 & $\mathbf{8 . 1}$ & 3 & $\mathbf{2 . 9}$ & 1 & 4.8 & 0.764 \\
\hline
\end{tabular}

Aortic Approach

$\begin{array}{lccccccc}\text { Total Arch Replac. } & 24 & \mathbf{6 4 . 9} & 52 & \mathbf{7 4 . 3} & 20 & \mathbf{9 5 . 2} & \mathbf{0 . 0 2 6} \\ \text { Hemiarch Replac. } & 13 & \mathbf{3 2 . 4} & 18 & \mathbf{2 5 . 7} & 1 & \mathbf{4 . 8} & \mathbf{0 . 0 2 6}\end{array}$

Additional Operation

\begin{tabular}{lccccccc} 
AVR & 2 & $\mathbf{5 . 4}$ & 3 & $\mathbf{4 . 3}$ & 1 & $\mathbf{4 . 8}$ & 1.0 \\
Bentall & 11 & $\mathbf{2 9 . 7}$ & 21 & $\mathbf{3 0 . 0}$ & 8 & $\mathbf{3 8 . 1}$ & 0.756 \\
David & 0 & $\mathbf{0 . 0}$ & 2 & $\mathbf{2 . 9}$ & 0 & $\mathbf{0 . 0}$ & 0.681 \\
Yacoub & 0 & $\mathbf{0 . 0}$ & 5 & $\mathbf{7 . 1}$ & 4 & $\mathbf{1 9 . 1}$ & $\mathbf{0 . 0 2 1}$ \\
CABG & 7 & $\mathbf{1 8 . 9}$ & 12 & $\mathbf{1 7 . 1}$ & 1 & $\mathbf{4 . 8}$ & 0.355 \\
\hline
\end{tabular}


Operation times were similar in all groups (Table 5); however, circulatory arrest group without selective perfusion had lower $\mathrm{CPB}$ - and circulatory arrest times. Conversely, the circulatory arrest group without perfusion required more often surgical revision than the groups where selective perfusion was used.

Surprisingly, no significant differences were assessed between the rates of surgical revision performed in the three groups (Table 5).

Table 5. Operative times and need for revision

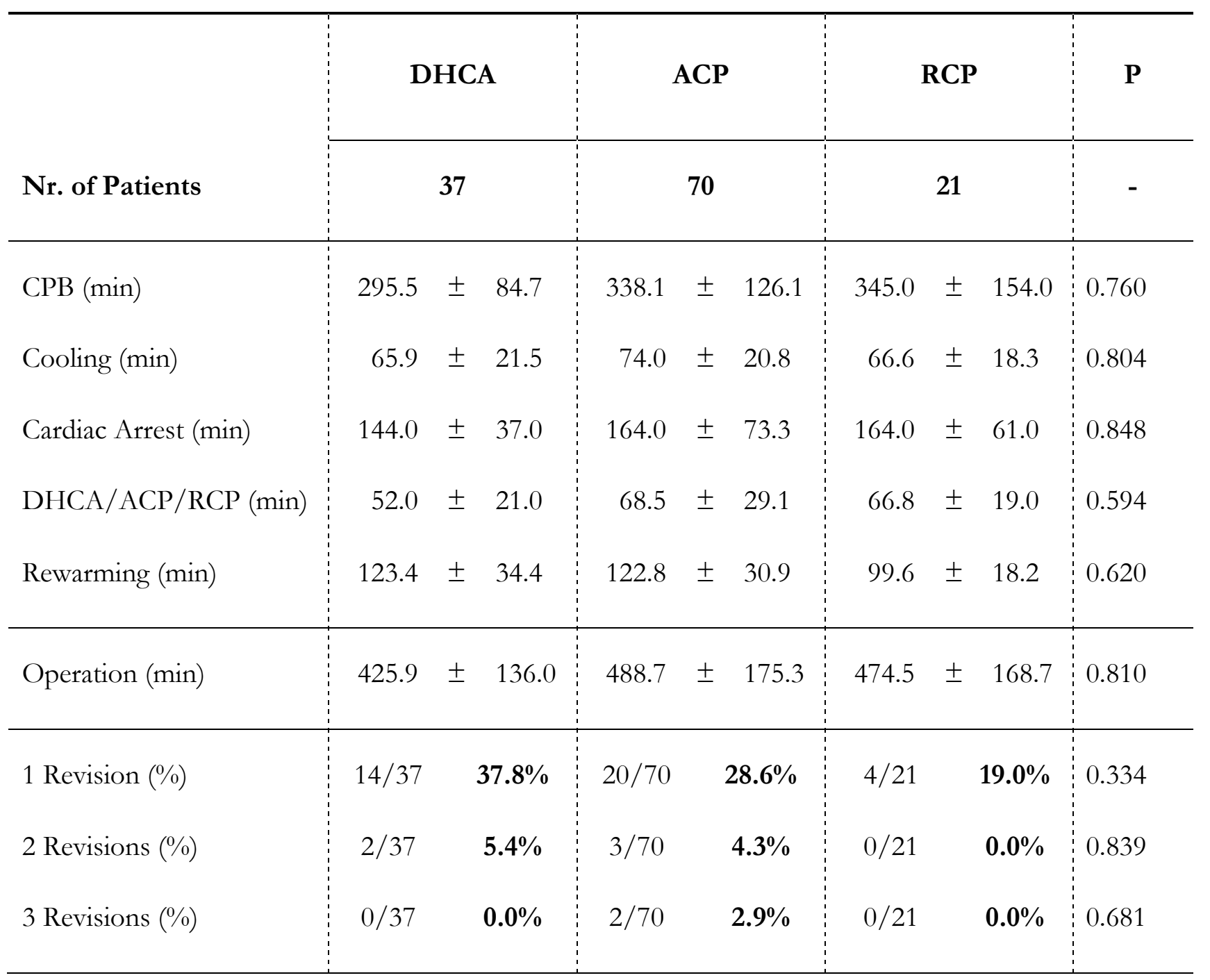

CPB cardiopulmonary bypass; DHCA/ACP/RCP, circulatory arrest time equaling antegrade and retrograde cerebral perfusion times in the ACP and RCP groups, respectively. $\mathrm{P}<0.05$ is statistically significant.

Only 1 of the total of 128 patients required laparotomy for hemicolectomy immediately after the aortic arch replacement because of extensive bowel necrosis, although antegrade cerebral perfusion and deep cooling had been used. This patient was pre-operatively 
diagnosed with an aortic dissection Type A involving the aortic arch, but not the descending aorta. No clinical signs of abdominal ischemia have been found, however, the pre-operative contrast-enhanced computer tomography scan revealed thickened and edematous intestinal wall with fluid retention. Re-thoracotomy was required on the first post-operative days because of hemodynamic instability. Surgical closure of the sternotomy was performed on the fourth post-operative day. The patient died on the $39^{\text {th }}$ postoperative day of multiorgan dysfunction.

However, the increased CPB- and cardiac arrest times (Table 5) seem to be related to the additional aortic root or cardiac reconstruction procedures rather than associated to the type of selective perfusion technique that was used (Figure 1).

The performance of additional cardiac procedures (presented in Table 4), significantly increased operation times, $\mathrm{CPB}$ times and cardiac arrest times in both antegrade and retrograde selective perfusion groups; however, without affecting cooling-, rewarming- and circulatory arrest periods (Figure 1).

Figure 1. Effect of additional cardiac and/or aortic root operation on the operative times

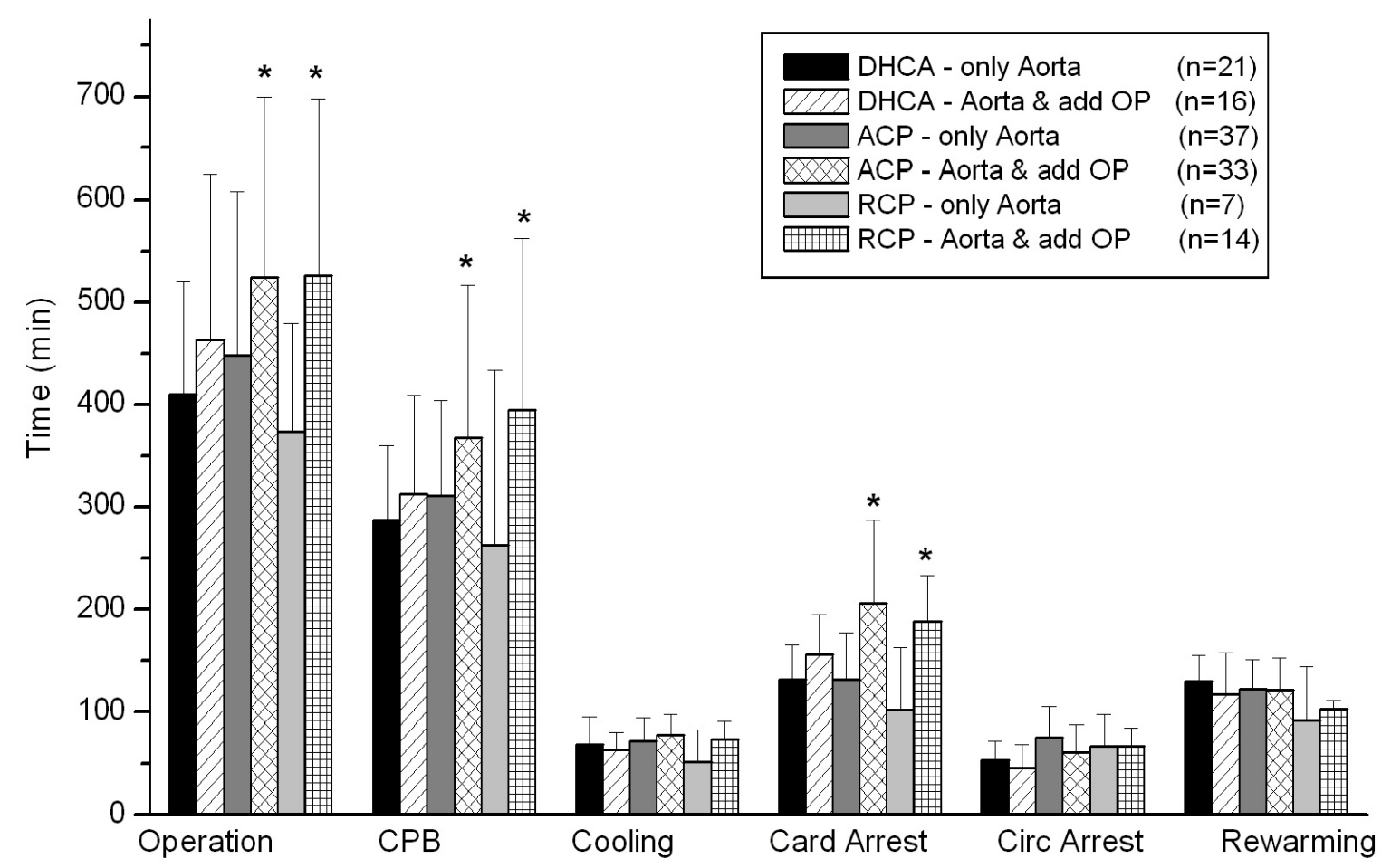

*, $\mathrm{p}<0.05$ Aorta $\&$ add OP vs only Aorta of the same cerebral protection group 


\subsubsection{Pharmacological Treatment}

Different catecholamine and buffer solutions have been used intra-operatively. A lower proportion of patients in the RCP group required catecholamine therapy during the operation (Figure 2) when compared to ACP and DHCA groups. However, no significant differences between the intra-operatively applied catecholamine-quantities were found (Figure 3) between the groups.

Figure 2. Proportion of patients requiring intra-operative catecholamines and buffer
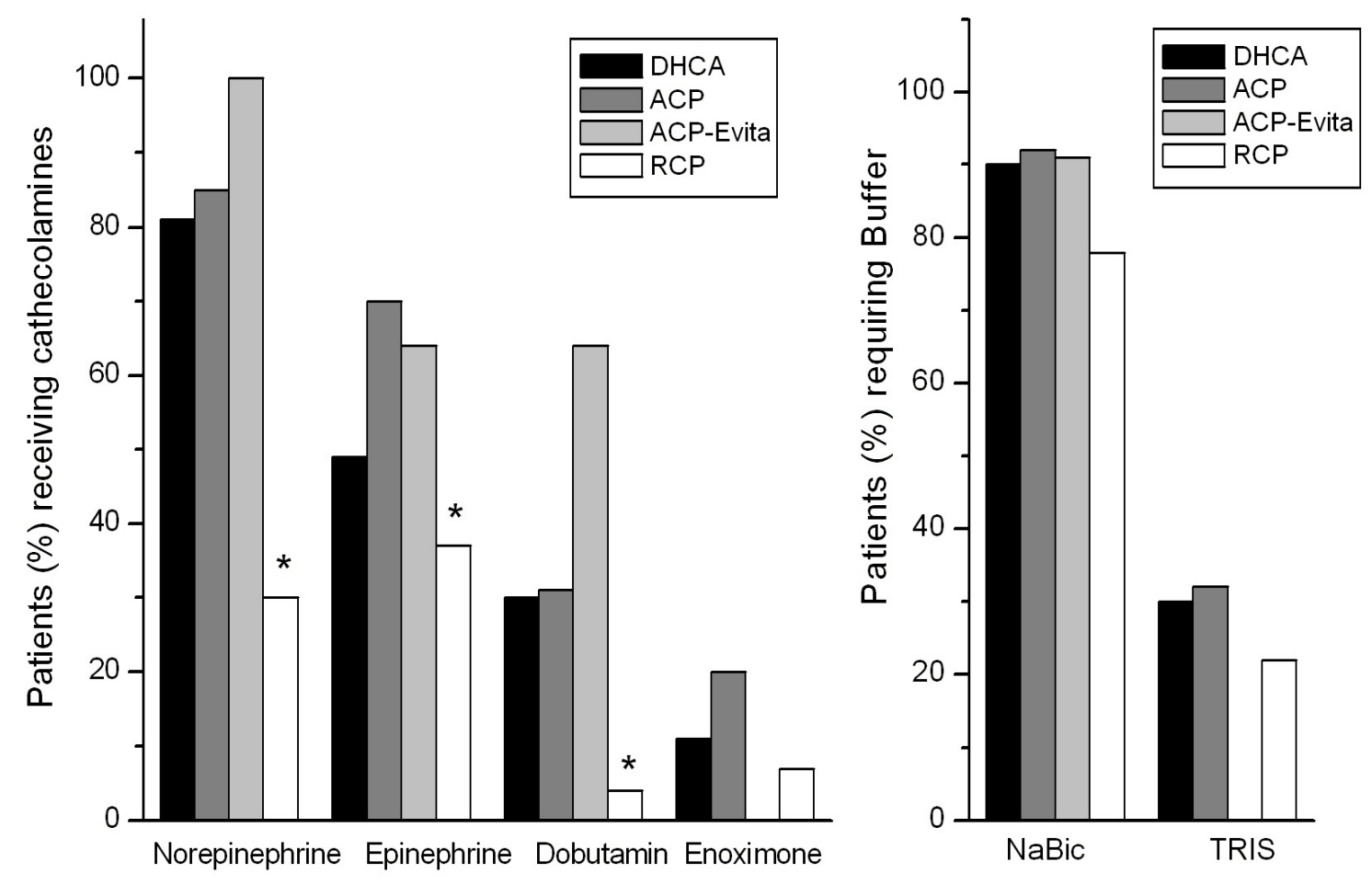

The percentage of patients requiring buffer and the quantities of buffer that have been administered did not differ between the groups (Figure 2, Figure 3).

At the beginning of the study period when mainly DHCA and RCP were used, transfusion of FFP was the main therapeutic tool for CPB-associated coagulopathy. More recently, when mostly ACP was applied, the availability of coagulation factors and thromboelastography diagnostic allowed selective application of coagulation factors thus, significantly reducing blood cells transfusion. 
Figure 3. Intra-operative application of catecholamines and buffer
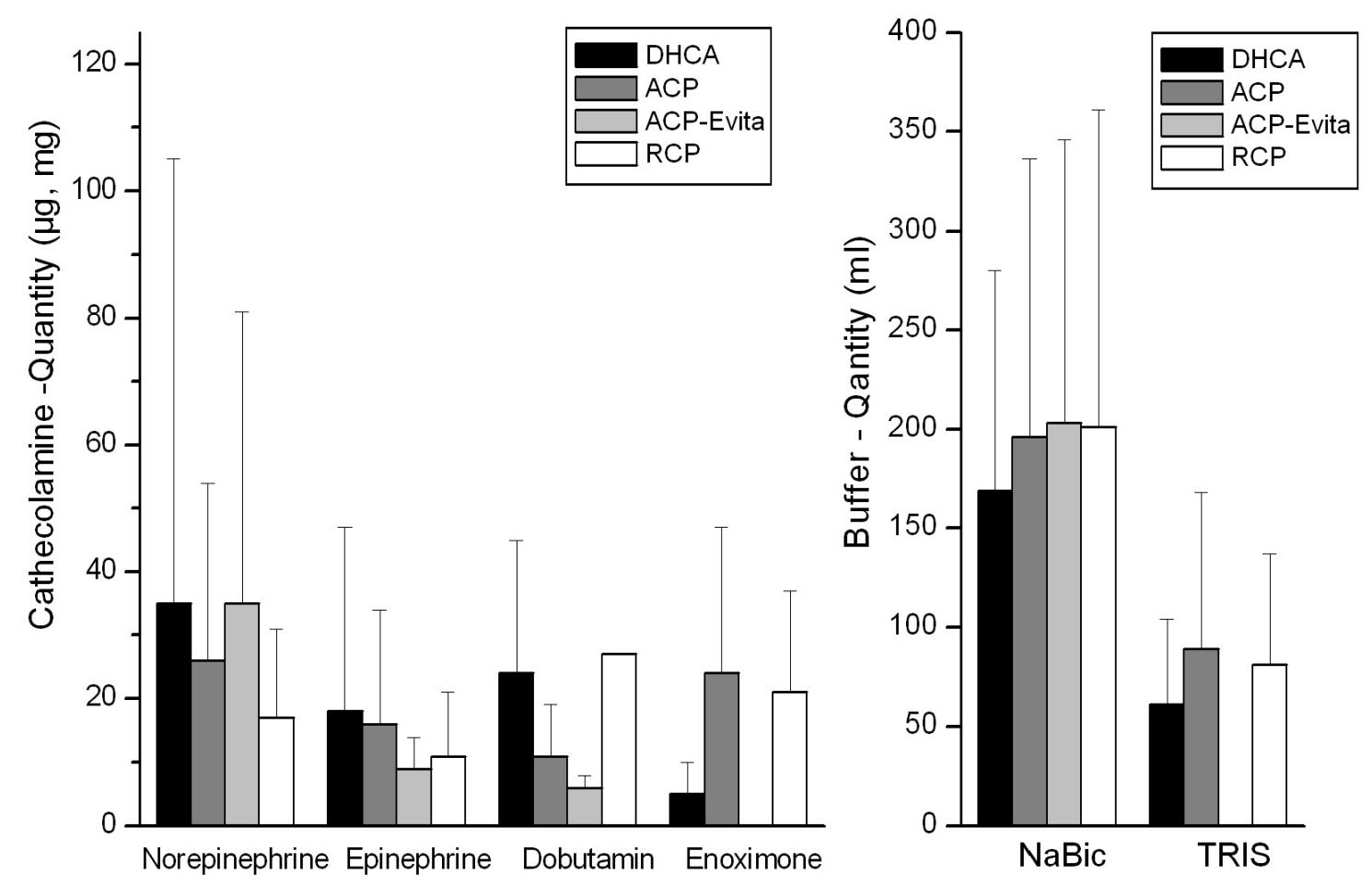

Figure 2, 3: DHCA, deep hypothermic circulatory arrest ( $\mathrm{n}=37)$; ACP, antegrade cerebral perfusion without Evita grafts ( $\mathrm{n}=59)$; ACP-Evita, antegrade cerebral perfusion with EVITA grafts ( $\mathrm{n}=11)$, RCP, retrograde cerebral perfusion $(\mathrm{n}=21) .{ }^{*}, \mathrm{p}<0.05$ vs ACP

Further analysis of blood transfusion quantity revealed that higher transfusion was used for RCP technique (Figure 5). Whereas no significances have been determined between the intra-operative transfusions in the DHCA, ACP and RCP groups, ACP-Evita graft implantation required significantly less PC and FFP administration than the RCP. Moreover, DHCA required less PCs and coagulation factors than ACP and RCP. Whereas ACP-Evita received more coagulation factors, ACP with classic FET implantation was associated with more PRBC and PC administration usually treated with coagulation factors. These findings correspond to the evolution in the treatment of intra-operative coagulopathies.

Whereas all three main groups showed similar post-operative outcome in terms of blood gas analysis, the RCP group required more catecholamines and more blood products during the operation than the DHCA and ACP groups. 
Figure 4. Proportion of patients requiring intra-operative blood replacement therapy

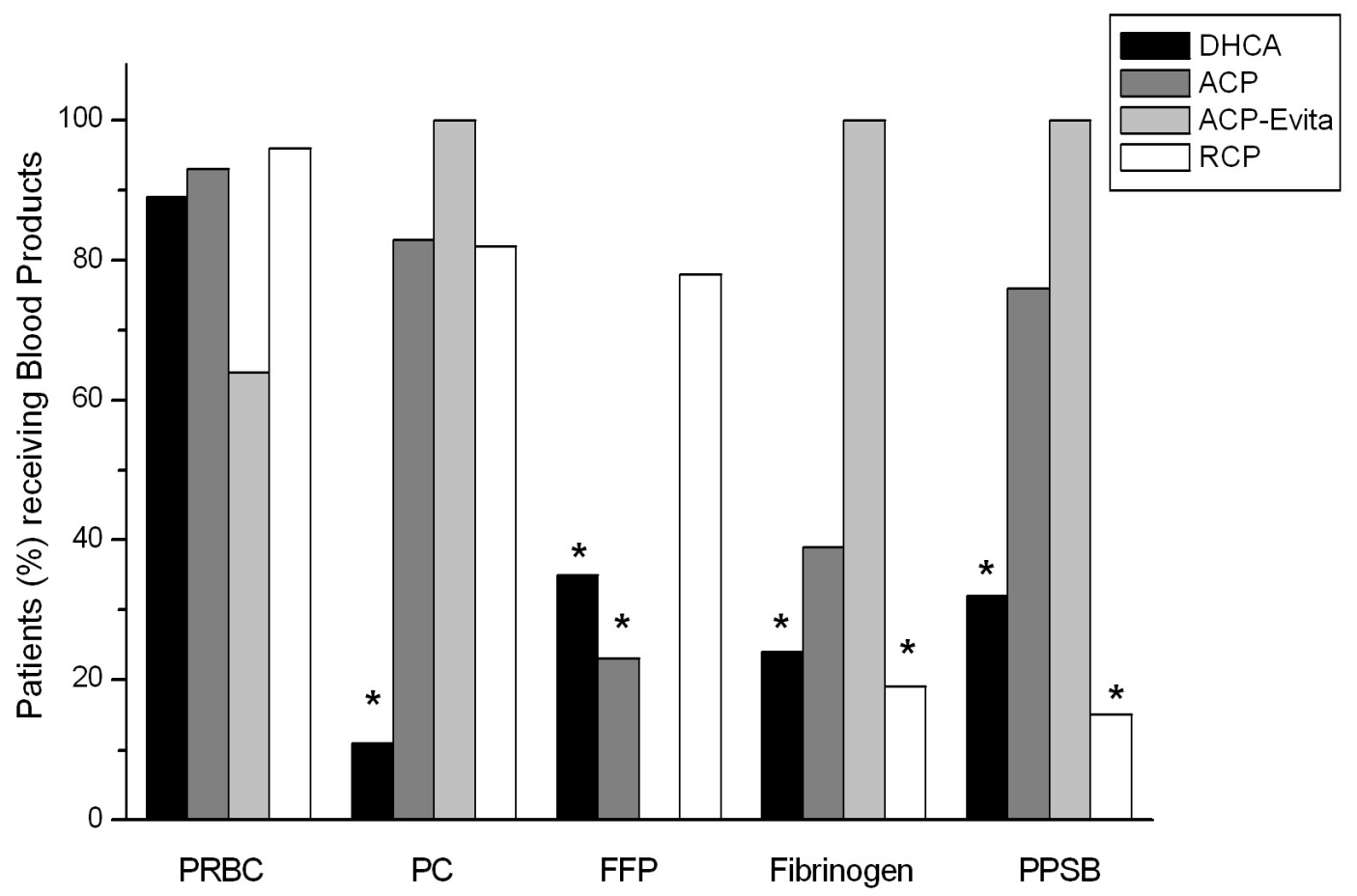

DHCA, deep hypothermic circulatory arrest $(\mathrm{n}=37)$; ACP, antegrade cerebral perfusion without Evita grafts $(\mathrm{n}=59)$; ACP-Evita, antegrade cerebral perfusion with EVITA grafts $(\mathrm{n}=11)$, RCP, retrograde cerebral perfusion $(\mathrm{n}=21)$. PRBC, packed red blood concentrate; PC, platelet concentrate; FFP, fresh frozen plasma; PPSB, prothrombin complex; *, $\mathrm{p}<0.05$ vs ACP-EVITA for PC, Fibrinogen, PPSB, and vs RCP for FFP.

Figure 5. Intra-operative administration of blood products

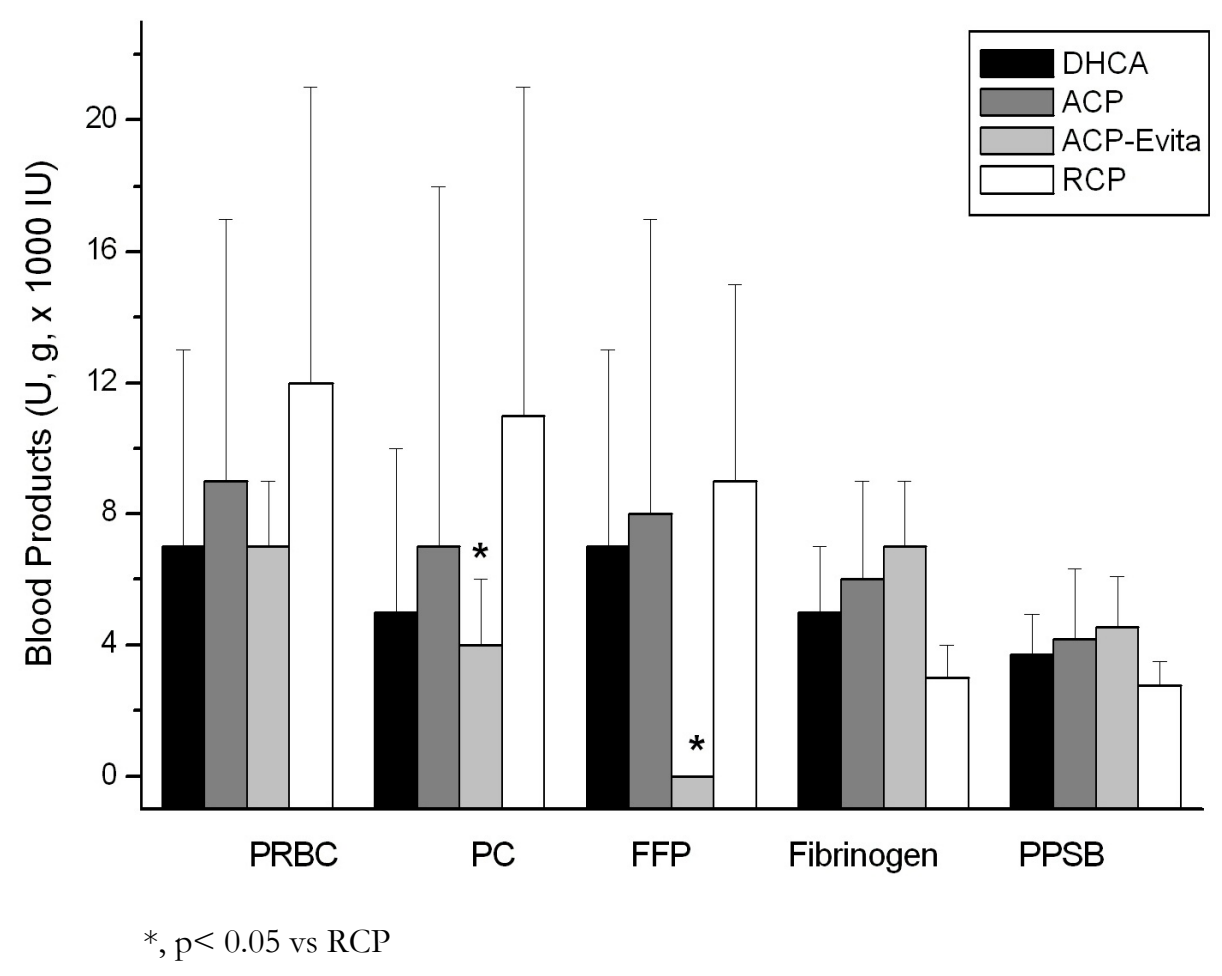




\subsubsection{Hemodynamics and Ventilation}

Comparable hemodynamics and pulmonary function of the patients is mirrored by the similar ventilatory support and hemodynamic variables at the end of the operation (Table $6)$.

Table 6. Post-operative hemodynamics and ventilation (at the end of the operation)

\begin{tabular}{|c|c|c|c|c|c|c|c|c|c|c|}
\hline \multirow{3}{*}{$\begin{array}{l}\text { Nr. of Patients } \\
\text { RR sys (mmHg) }\end{array}$} & \multicolumn{3}{|c|}{ DHCA } & \multicolumn{3}{|c|}{$\mathrm{ACP}$} & \multicolumn{3}{|c|}{$\mathbf{R C P}$} & \multirow{3}{*}{$\begin{array}{c}\mathbf{P} \\
- \\
0.909\end{array}$} \\
\hline & \multicolumn{3}{|c|}{37} & \multicolumn{3}{|c|}{70} & \multicolumn{3}{|c|}{21} & \\
\hline & 96.9 & \pm & 17.3 & 98.1 & \pm & 24.2 & 100.4 & \pm & 26.4 & \\
\hline $\mathrm{RR}$ diast $(\mathrm{mmHg})$ & 50.8 & \pm & 9.7 & 52.4 & \pm & 14.4 & 58.9 & \pm & 17.7 & 0.661 \\
\hline$P$ insp & 21.0 & \pm & 3.6 & 19.8 & \pm & 4.3 & 20.9 & \pm & 4.2 & 0.854 \\
\hline PEEP & 6.8 & \pm & 1.7 & 6.3 & \pm & 1.6 & 7.0 & \pm & 2.2 & 0.823 \\
\hline $\mathrm{FiO}_{2}(\%)$ & 0.9 & \pm & 0.3 & 0.9 & \pm & 0.2 & 0.9 & \pm & 0.2 & 0.948 \\
\hline
\end{tabular}

Figure 6. Post-operative arterial lactate values in the subgroups (at the end of the operation)

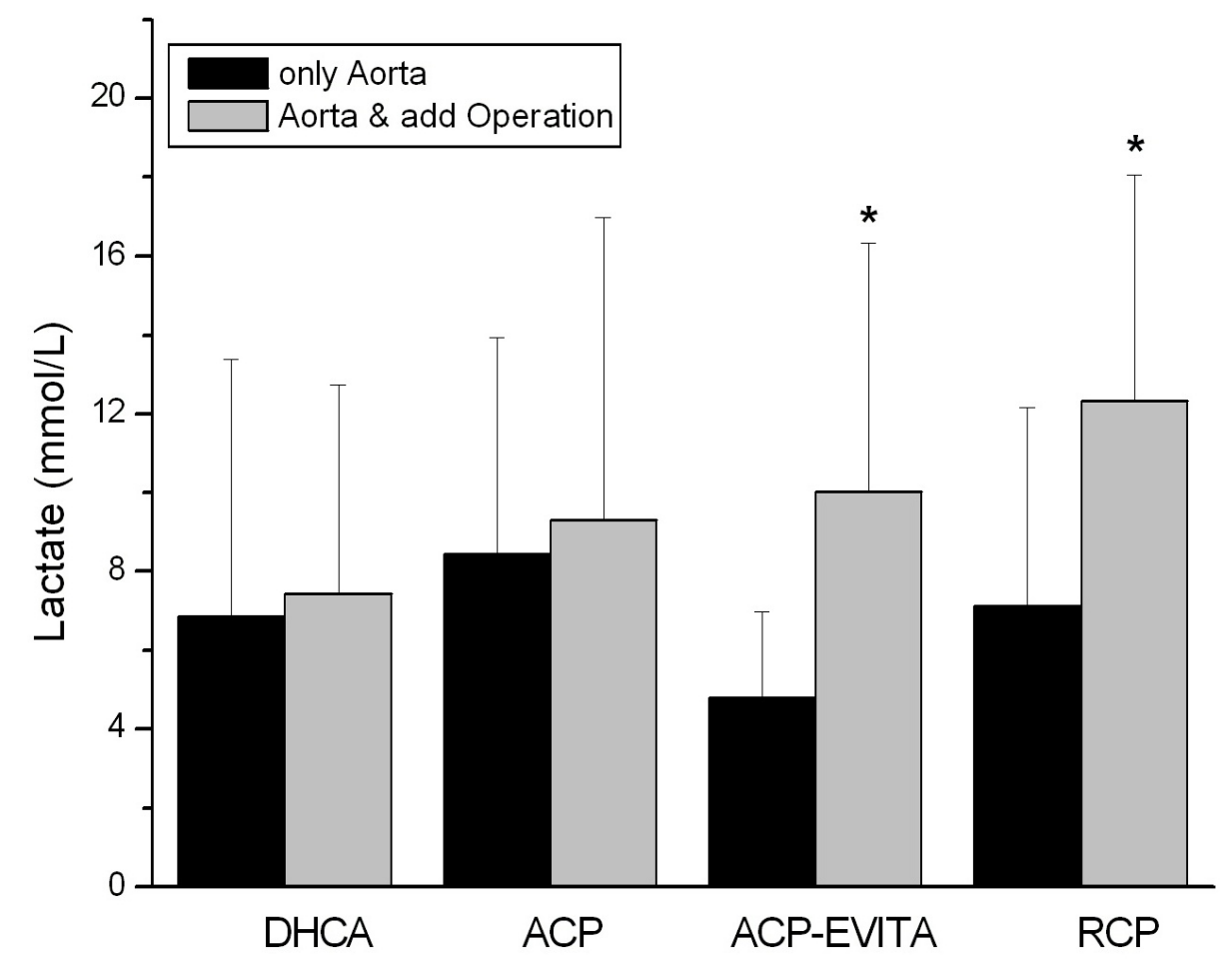

*, p $<0.05$ Aorta \& additional operation group vs only Aorta group 


\subsubsection{Blood Gas Analysis}

The pre-operative (Table 7) and post-operative (Table 8) blood gas analysis revealed no differences between the groups. No significant differences were found between the blood gas values of the three main groups before the operation, however slightly higher lactate values were observed post-operatively in the ACP and RCP groups, without reaching the level of significance.

Whereas the lactate values were not influenced by the performance of additional cardiac operation in the DHCA and ACP subgroups (Figure 6), the use of the EVITA system tended to be associated with lower lactate values in the pure aortic surgery group. Lower lactate levels were found in the pure aortic groups operated with ACP-EVITA and RCP (Figure 6).

Table 7. Pre-operative blood gas analysis (at the beginning of the operation)

\begin{tabular}{|c|c|c|c|c|c|c|}
\hline & DHCA & ACP & \multicolumn{3}{|c|}{ RCP } & $\mathbf{P}$ \\
\hline Nr. of Patients & 37 & 70 & & 21 & & - \\
\hline $\mathrm{pH}$ & $7.4 \pm 0.1$ & $7.4 \pm 0.1$ & 7.4 & \pm & 0.1 & 1.0 \\
\hline $\mathrm{pO}_{2}$ & $164.8 \pm 132.7$ & $181.1 \pm 133.8$ & 189.8 & \pm & 134.5 & 0.899 \\
\hline $\mathrm{pCO}_{2}$ & $43.5 \pm 3.6$ & $43.4 \pm 7.3$ & 43.3 & \pm & 11.9 & 0.984 \\
\hline $\mathrm{SaO}_{2}$ & $94.9 \pm 5.6$ & $95.1 \pm 11.6$ & 95.2 & \pm & 11.4 & 0.979 \\
\hline $\mathrm{Hb}$ & $11.2 \pm 2.6$ & $12.2 \pm 3.8$ & 12.6 & \pm & 1.9 & 0.709 \\
\hline Htc & $37.1 \pm 6.1$ & $36.3 \pm 7.0$ & 36.7 & \pm & 10.3 & 0.934 \\
\hline Base Excess & $-2.4 \pm 5.3$ & $-1.5 \pm 4.7$ & -2.9 & \pm & 4.9 & 0.876 \\
\hline $\mathrm{HCO}_{3}$ & $23.4 \pm 3.6$ & $24.1 \pm 4.4$ & 22.2 & \pm & 3.8 & 0.819 \\
\hline $\mathrm{K}^{+}$ & $3.9 \pm 1.1$ & \pm 3.5 & 3.9 & \pm & 0.7 & 0.950 \\
\hline Lactate & $2.8 \pm 3.9$ & $2.5 \pm 2.9$ & 2.8 & \pm & 2.4 & 0.951 \\
\hline
\end{tabular}

Table 6, Table 7, Table 8: RR sys, systolic blood pressure, RR dias, diastolic blood pressure; P insp., inspiratory oxygen pressure; $\mathrm{p}<0.05$ is statistically significant. 
Table 8. Post-operative blood gas analysis (at the end of the operation)

\begin{tabular}{|c|c|c|c|c|}
\hline & DHCA & ACP & RCP & $\mathbf{P}$ \\
\hline Nr. of Patients & 37 & 70 & 21 & - \\
\hline $\mathrm{pH}$ & $7.34 \pm 0.07$ & $7.32 \pm 0.11$ & $7.33 \pm 0.16$ & 0.900 \\
\hline $\mathrm{pO}_{2}$ & $274.7 \pm 121.7$ & \pm 148.9 & $253.6 \pm 158.9$ & 0.916 \\
\hline $\mathrm{pCO}_{2}$ & \pm 8.3 & \pm 8.2 & \pm 15.9 & 0.949 \\
\hline $\mathrm{SaO}_{2}$ & \pm 1.9 & $94.9 \pm 18.3$ & $95.5 \pm 7.8$ & 0.859 \\
\hline $\mathrm{Hb}$ & $9.5 \pm 1.4$ & \pm 4.3 & \pm 1.5 & 0.821 \\
\hline Htc & \pm 4.3 & \pm 13.8 & \pm 4.6 & 0.847 \\
\hline Base Excess & $-2.6 \pm 3.9$ & $-4.4 \pm 5.3$ & \pm 5.6 & 0.777 \\
\hline $\mathrm{HCO}_{3}$ & $22.9 \pm 3.5$ & \pm 4.1 & \pm 5 & 0.764 \\
\hline $\mathrm{K}^{+}$ & \pm 0.7 & \pm 0.7 & \pm 0.6 & 0.847 \\
\hline Lactate & \pm 4.3 & \pm 5.7 & \pm 5.4 & 0.523 \\
\hline
\end{tabular}

Table 6, Table 7, Table 8: RR sys, systolic blood pressure, RR dias, diastolic blood pressure; P insp., inspiratory oxygen pressure; $\mathrm{p}<0.05$ is statistically significant.

\subsection{Post-operative Evaluation}

\subsubsection{Intensive Care Treatment}

No significant differences in terms of intubation, renal replacement therapy and pharmacologic support have been post-operatively observed between the three groups (Table 9). Moreover, intra-operative cerebral perfusion did not influence the length of the post-operative mechanical ventilation (Table 10). 
Table 9. Intensive care therapy

\begin{tabular}{|c|c|c|c|c|c|c|c|}
\hline \multirow[b]{2}{*}{ Nr. of Patients } & \multicolumn{2}{|r|}{ DHCA } & \multicolumn{2}{|r|}{ ACP } & \multicolumn{2}{|c|}{ RCP } & \multirow{2}{*}{$\begin{array}{l}\mathbf{P} \\
-\end{array}$} \\
\hline & 25 & days & 52 & days & 12 & days & \\
\hline Intubation-time & 25 & $6.1 \pm 15.0$ & 52 & $5.4 \pm 8.5$ & 12 & $6.2 \pm 7.7$ & 0.965 \\
\hline Renal repl. therapy & 9 & $6.2 \pm 2.9$ & 13 & $8.2 \pm 6.1$ & 2 & $9.5 \pm 1.5$ & 0.620 \\
\hline Buffer & 18 & $2.3 \pm 1.0$ & 39 & $2.1 \pm 0.6$ & 4 & $1.5 \pm 0.5$ & 0.716 \\
\hline Catechol. & 24 & \pm 8.2 & 51 & $4.4 \pm 3.9$ & 10 & $4.4 \pm 4.1$ & 0.880 \\
\hline AB Therapy & 24 & $9.8 \pm 18.5$ & 51 & $7.7 \pm 8.4$ & 12 & $7.1 \pm 7.3$ & 0.920 \\
\hline
\end{tabular}

Table 10. Mechanical ventilation times

\begin{tabular}{|c|c|c|c|c|c|c|c|}
\hline \multirow[b]{2}{*}{ Nr. of Patients } & \multicolumn{2}{|c|}{ DHCA } & \multicolumn{2}{|c|}{ ACP } & \multicolumn{2}{|c|}{$\mathbf{R C P}$} & \multirow{2}{*}{$\begin{array}{l}\mathbf{P} \\
-\end{array}$} \\
\hline & 25 & $\%$ & 52 & $\%$ & 12 & $\%$ & \\
\hline Ventilation $<24 \mathrm{~h}$ & 11 & 44.0 & 20 & 38.0 & 5 & 42.0 & 0.952 \\
\hline Ventilation $24 \mathrm{~h}-72 \mathrm{~h}$ & 6 & 24.0 & 12 & 23.0 & 1 & 8.0 & 0.615 \\
\hline Ventilation $4 d-10 d$ & 6 & 24.0 & 14 & 27.0 & 3 & 25.0 & 1.0 \\
\hline Ventilation $>10 \mathrm{~d}$ & 2 & 8.0 & 6 & 12.0 & 3 & 25.0 & 0.384 \\
\hline
\end{tabular}

Data of patients surviving the intensive care stay; $h$, hours; $d$, days.

\subsubsection{Hemodynamic Monitoring}

In terms of cardiac function, only monitoring of the DHCA $(n=11)$ and ACP $(n=18)$ patients allowed CO and CI calculations. The data of the RCP patients could not be quantified because no monitoring was performed in this group. No significant differences were assessed between the DHCA and ACP groups (Figure 7). 
Figure 7. Early post-operative cardiac function
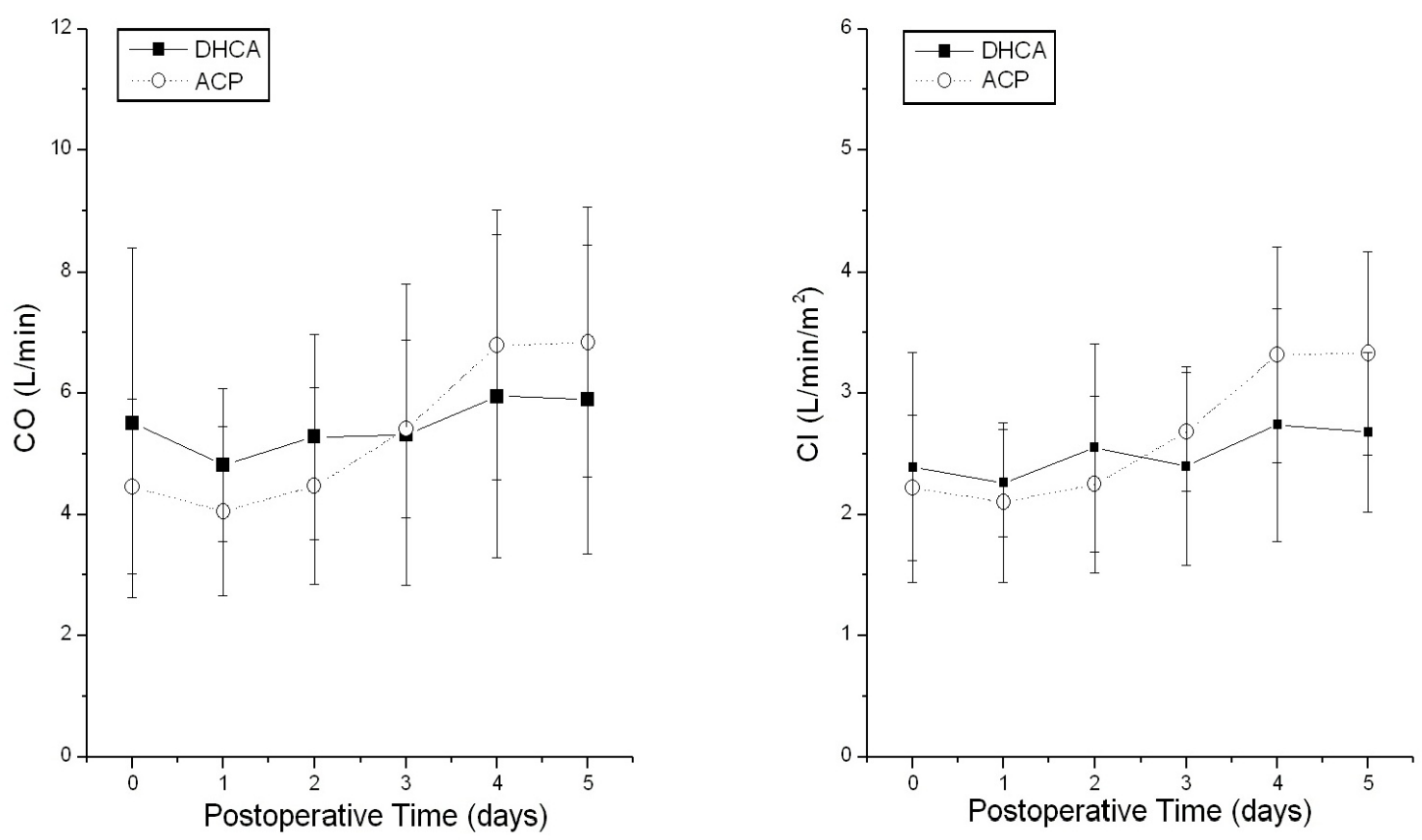

CO, Cardiac output; CI, cardiac index. Data were documented in 11 circulatory arrest and 21 antegrade cerebral perfusion patients. Mean $\pm \mathrm{SD}$ values are represented.

\subsubsection{Pharmacological Treatment}

A significant difference was assessed between the amounts of catecholamine administered during the post-operative period.

As revealed by the catecholamine index calculations, both ACP and RCP patients required significantly less catecholamine support than DHCA patients during the first 30 postoperative days (Figure 8).

No significant difference in term of blood transfusion requirements, buffer or coagulation therapy was assessed between the groups (Figure 9). RCP patients receiving additional operations seem to require more transfusion post-operatively; however, these differences did not reach the level of significance (Figure 10).

The use of Evita system was not associated with lower need for transfusion or buffer administration during the post-operative period (Figure 10). 
Figure 8. Post-operative catecholamine support

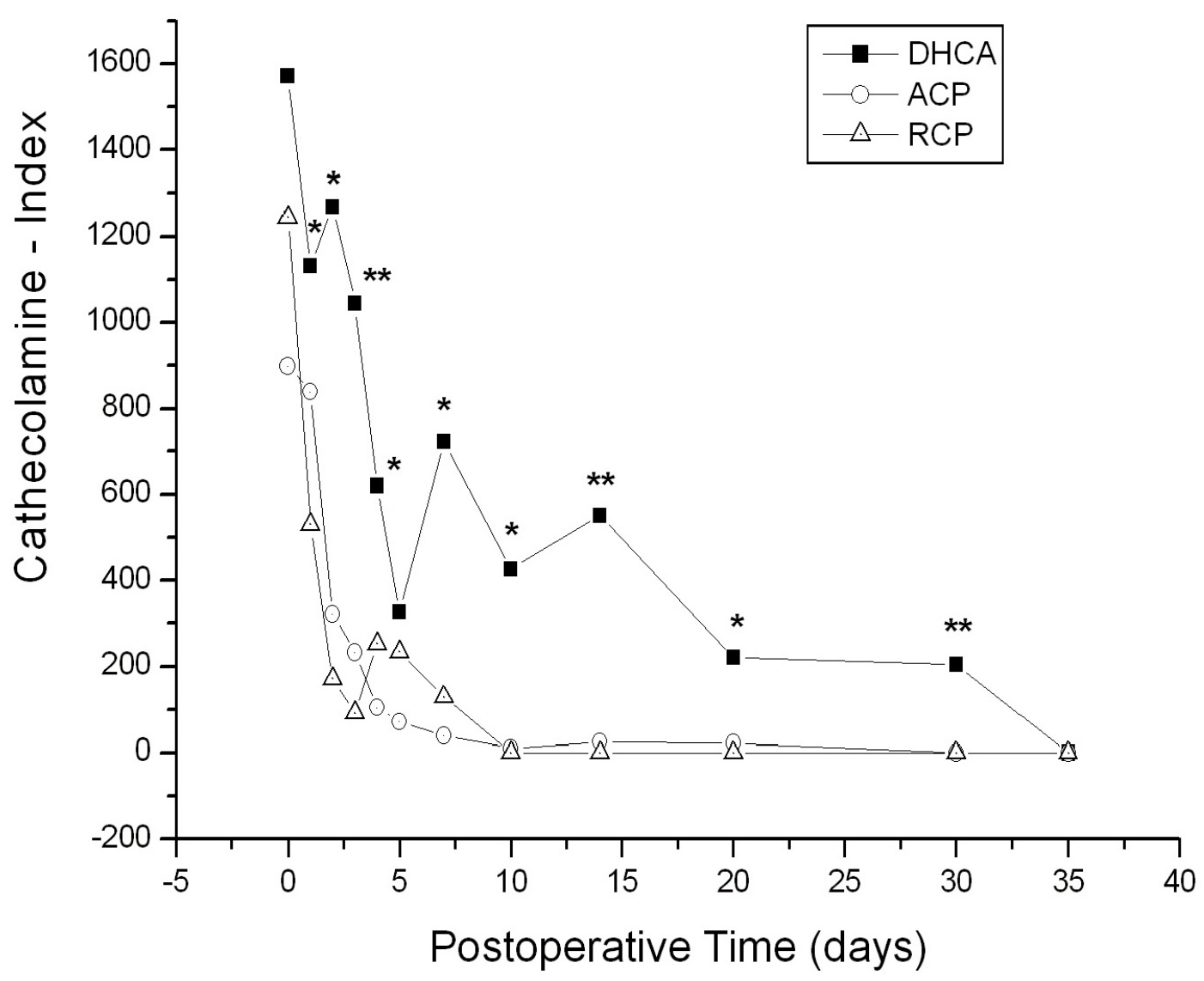

${ }^{*}, \mathrm{p}<0.05,{ }^{* *}, \mathrm{p}<0.01$ for circulatory arrest vs antegrade perfusion

\subsection{Laboratory Analysis of Abdominal Markers}

Whereas GPT was an early post-operative marker of hepatic damage, GGT remained unchanged in all groups during the first 5 post-operative days (Figure 11). Similarly, inflammation seems to be a delayed process that appears unchanged during the first 5 postoperative days and intensifies thereafter (Figure 12).

In terms of gastrointestinal ischemic injury, lactate values increase early during the preoperative and intra-operative ischemia time, whereas CK appears to increase mostly after the reperfusion phase (Figure 13). Both changed relevantly in the early post-operative phase and returned to baseline levels after the $5^{\text {th }}$ post-operative day.

Renal function markers increased progressively during the first 5 post-operative days and remained elevated almost in all cases during the entire hospital stay (Figure 14). 
Figure 9. Incidence of post-operative blood replacement therapy (ICU)
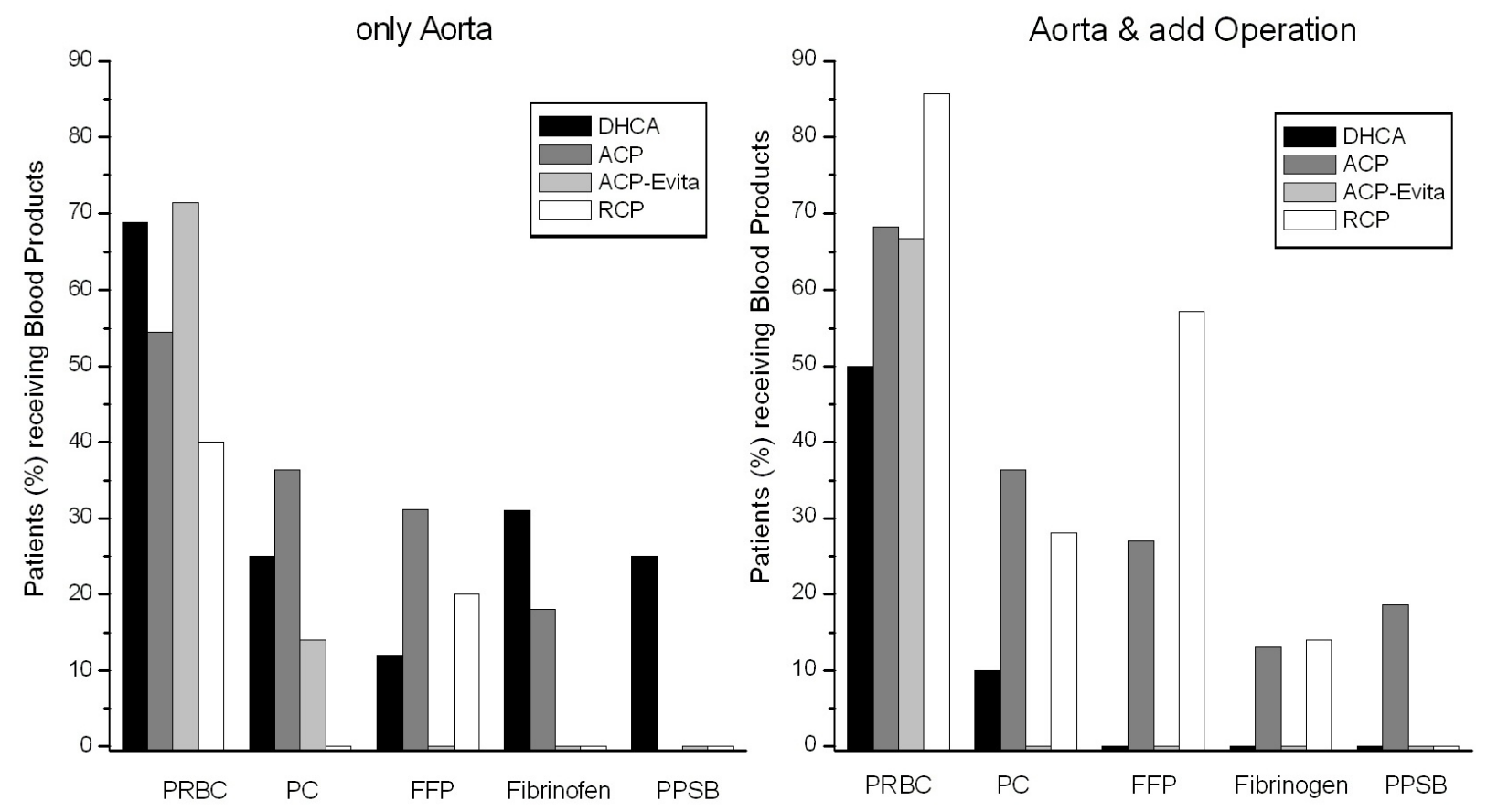

Figure 10. Magnitude of post-operative blood replacement therapy (ICU)

\section{only Aorta}

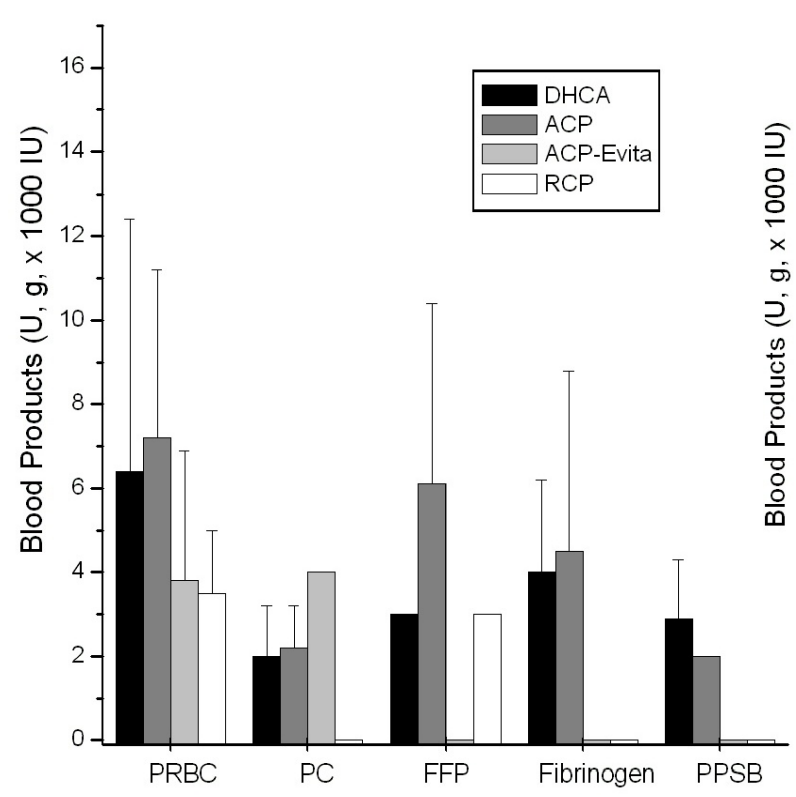

Aorta \& add Operation

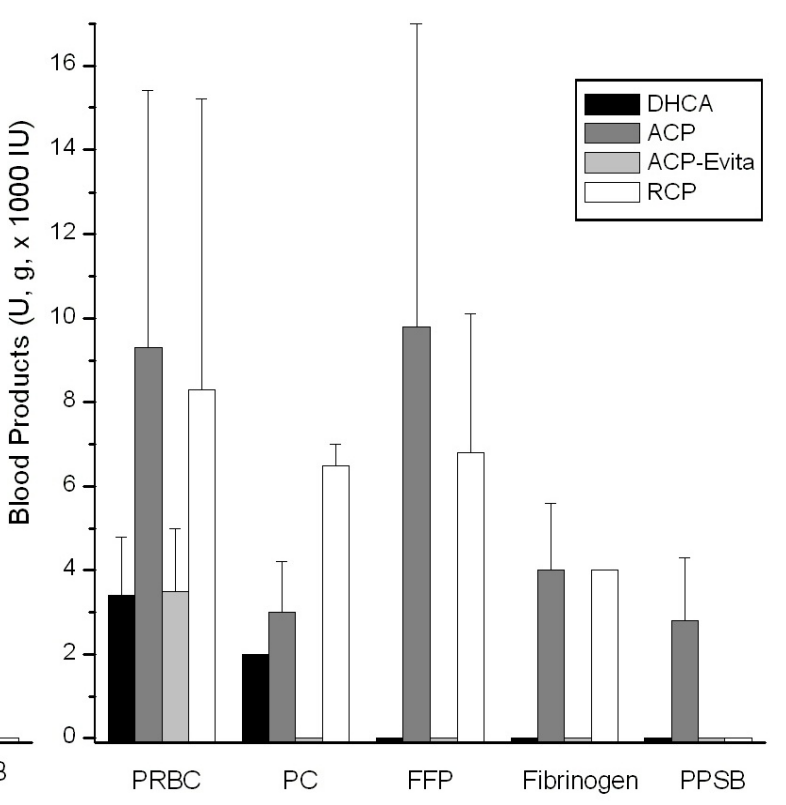

DHCA, deep hypothermic circulatory arrest $(\mathrm{n}=37)$; ACP, antegrade cerebral perfusion without Evita grafts $(\mathrm{n}=59)$; ACP-Evita, antegrade cerebral perfusion with EVITA grafts $(\mathrm{n}=11)$, RCP, retrograde cerebral perfusion $(\mathrm{n}=21)$. PRBC, packed red blood concentrate; PC, platelet concentrate; FFP, fresh frozen plasma; PPSB, prothrombin complex; $*$, $<<0.05$ vs ACP-EVITA for PC, fibrinogen, PPSB, and vs RCP for FFP. 
Figure 11. Markers of hepatic function
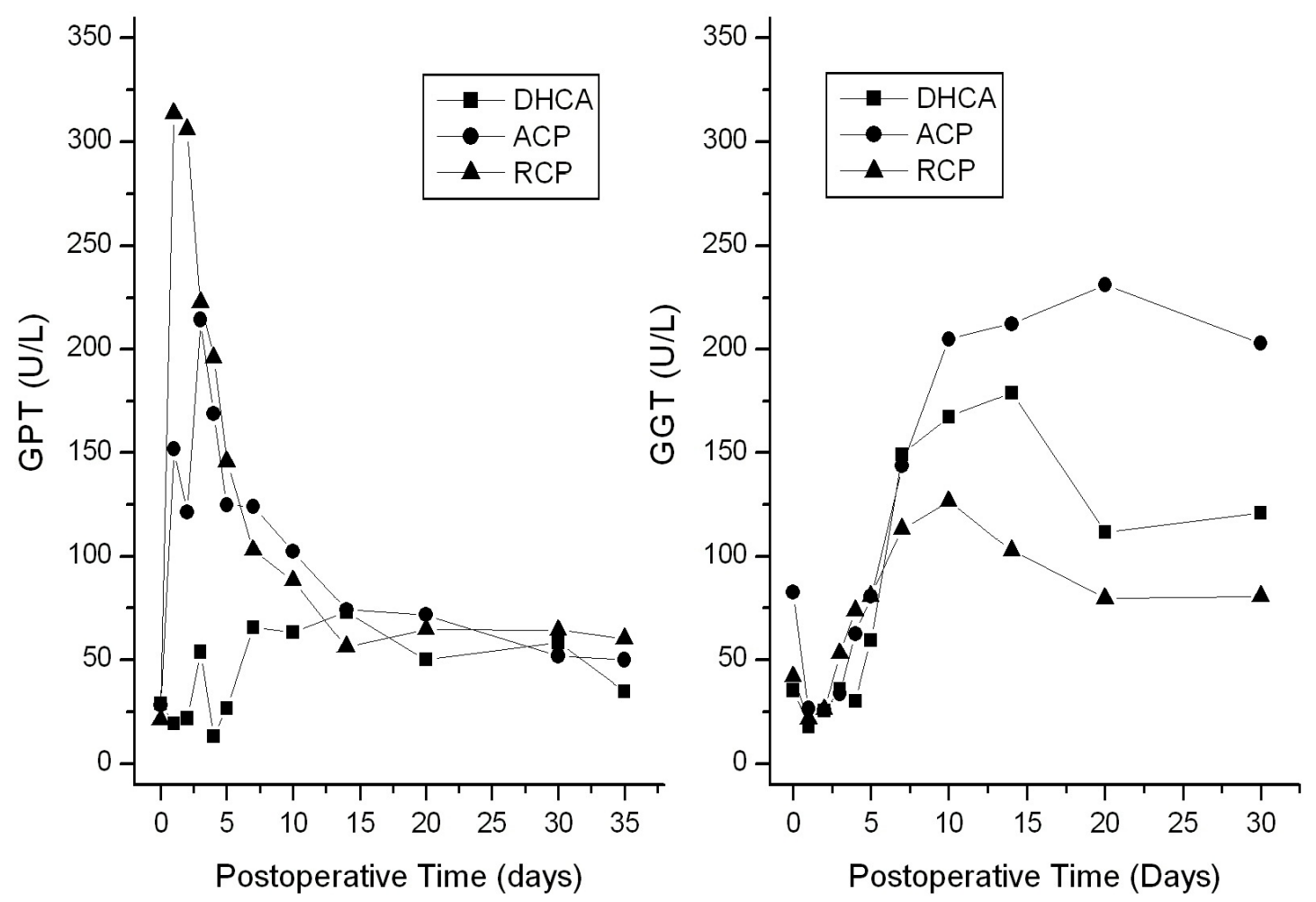

Figure 12. Markers of gastrointestinal inflammation
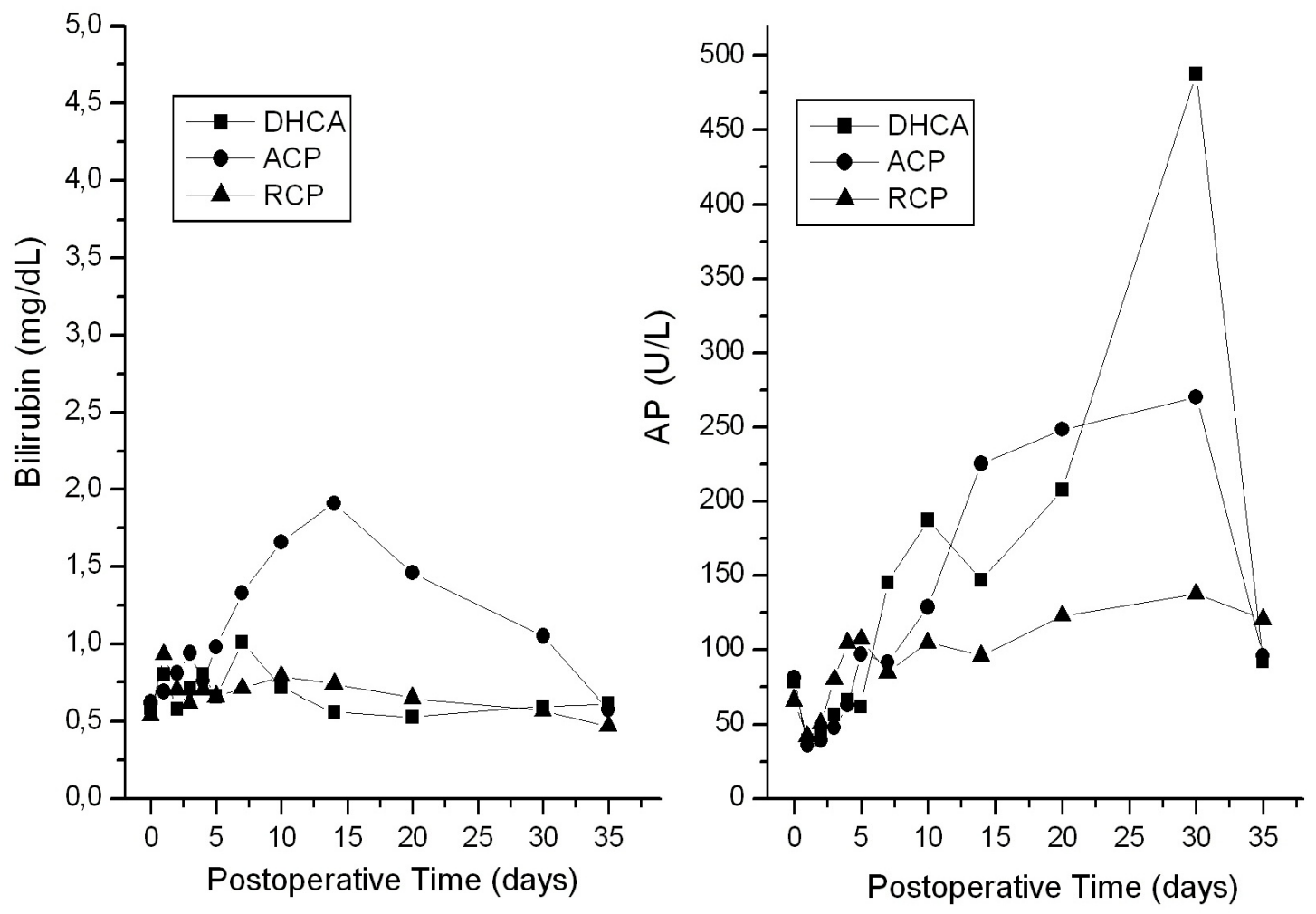

Mean values of laboratory parameters are represented. DHCA, deep hypothermic circulatory arrest $(n=37)$; ACP, antegrade cerebral perfusion $(n=70)$; RCP, retrograde cerebral perfusion $(n=21)$. 
Figure 13. Markers of intestinal ischemia/reperfusion injury
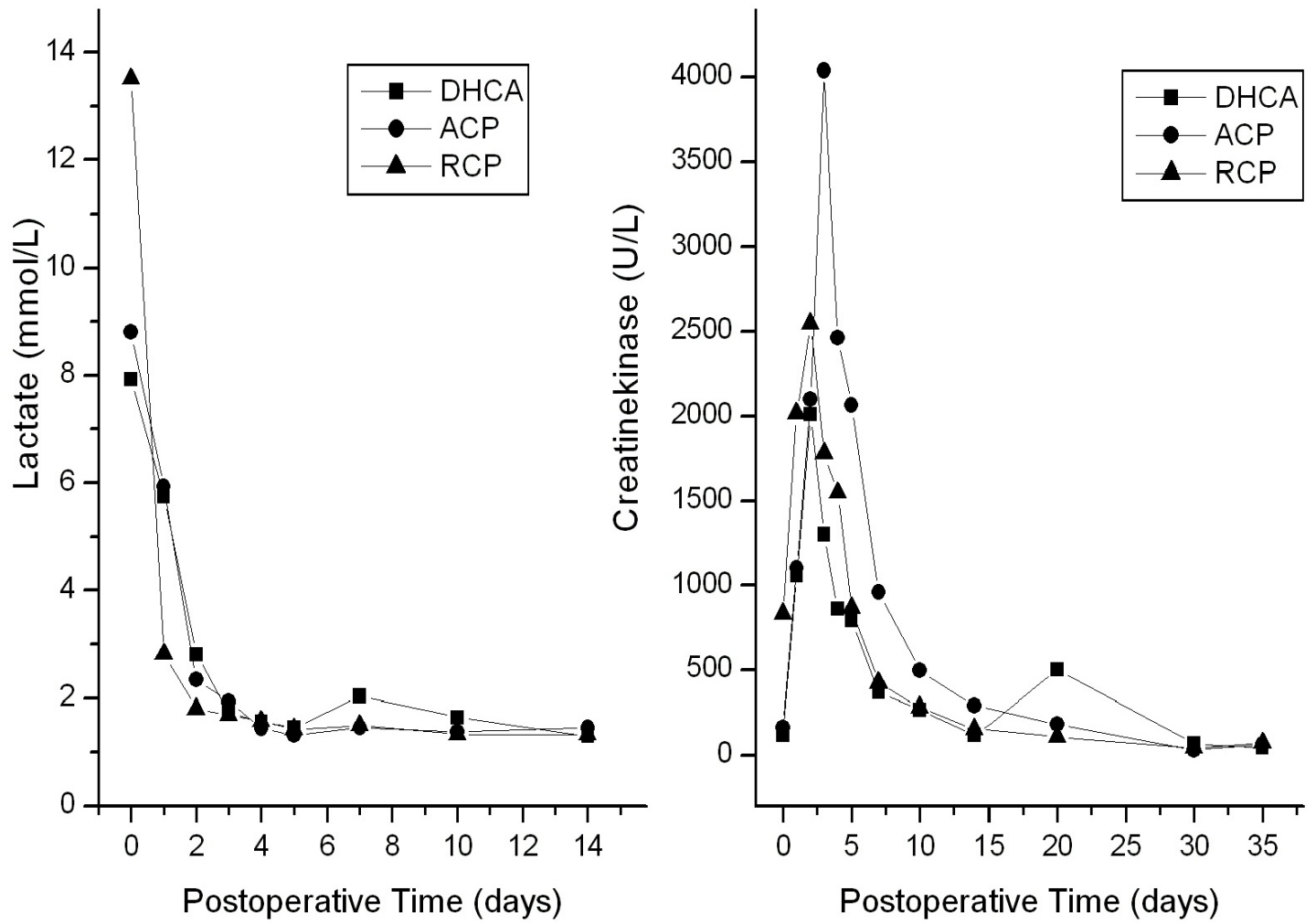

Figure 14. Markers of renal function
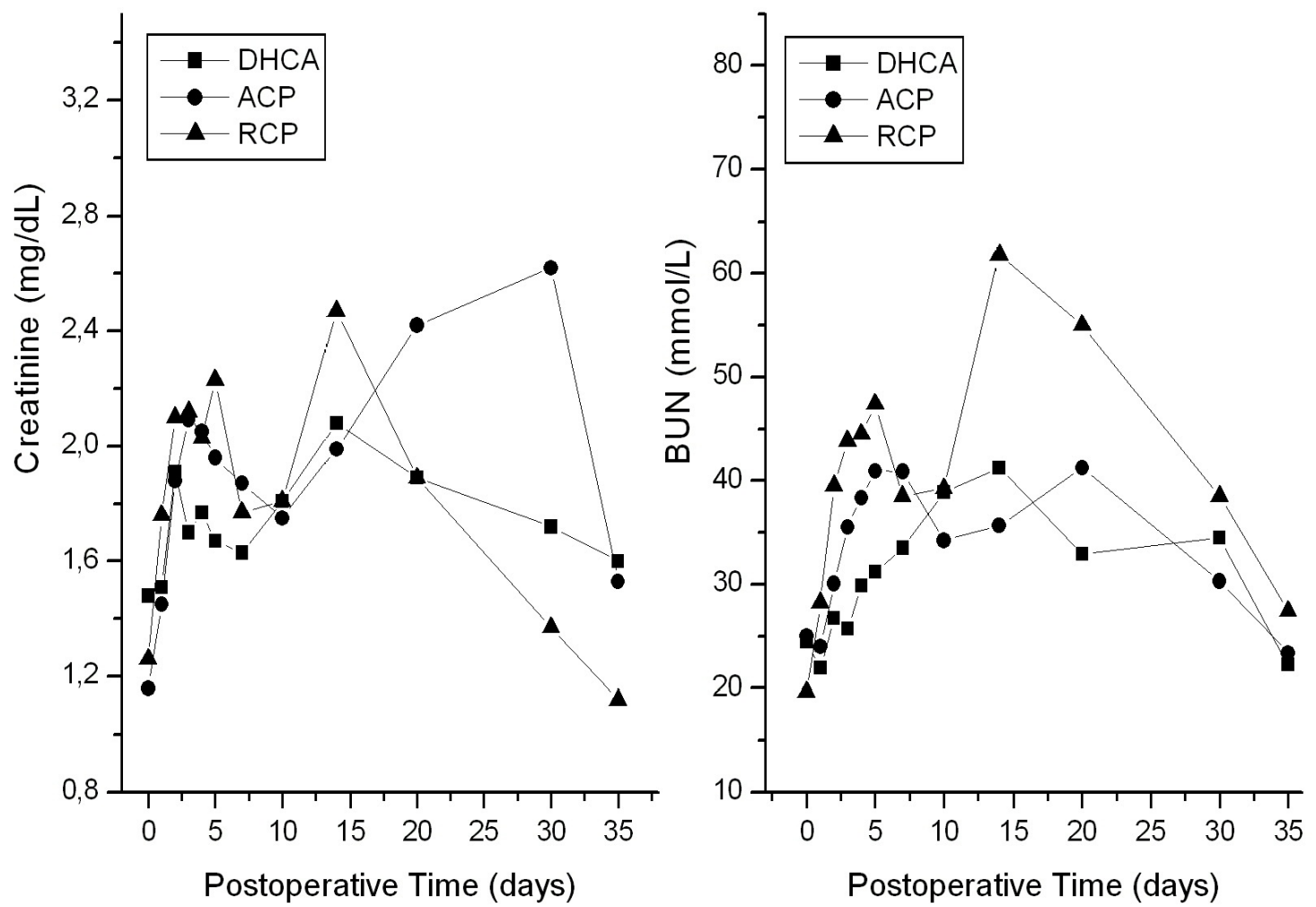

Mean values of laboratory parameters are represented. DHCA, deep hypothermic circulatory arrest $(n=37)$; ACP, antegrade cerebral perfusion $(n=70)$; RCP, retrograde cerebral perfusion $(n=21)$. 
Because of the heterogeneity of the three main groups and the small number of individuals protected by RCP, no significant differences for any of the markers could be revealed at any time during the evaluation.

\subsection{Duration of Post-operative Care}

The different types of circulatory support did not influence the intensive care therapy time or the hospital stay in our study (Figure 15).

Hospital stay (Figure 15) was comparable between the groups: $22.84 \pm 27.93$ days (DHCA), $19.89 \pm 13.8$ days (ACP) and $17.87 \pm 10.85$ days (RCP).

Figure 15. Duration of post-operative care

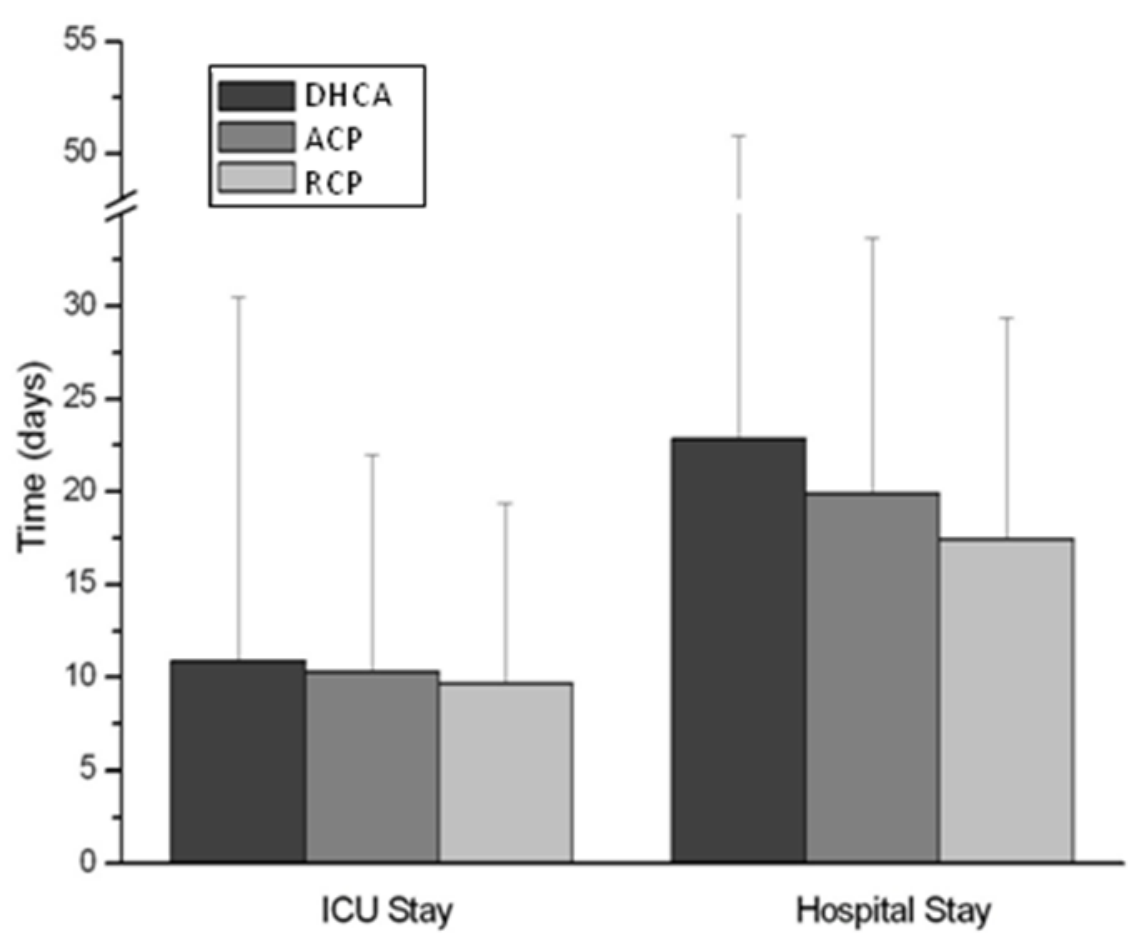

DHCA, deep hypothermic circulatory arrest; ACP antegrade cerebral perfusion; RCP, retrograde cerebral perfusion. Mean values of patients surviving the intensive care stay (23, 57 and 14 patients) and hospital stay (19, 51 and 13 patients), DHCA, ACP and RCP respectively, are represented 


\subsection{Mortality}

Overall mortality was not influenced by the type of cerebral protection applied. The first 48 post-operative hours are characterized by the highest mortality rates and thus remain the critical time-frame in all the subgroups (Table 11). Performance of additional surgery similarly increased mortality in all groups, however without reaching the level of significance, probably because of the small sample sizes (Table 12).

Table 11. Overall mortality

\begin{tabular}{|c|c|c|c|c|c|c|c|c|}
\hline \multirow[b]{2}{*}{ Nr. of Patients } & \multicolumn{2}{|c|}{ DHCA } & \multicolumn{2}{|c|}{ ACP } & \multicolumn{2}{|c|}{ RCP } & \multirow{2}{*}{$\begin{array}{l}\mathbf{P} \\
-\end{array}$} & \multirow{2}{*}{$\begin{array}{r}1-\beta \\
\%\end{array}$} \\
\hline & 37 & $\%$ & 70 & $\%$ & 21 & $\%$ & & \\
\hline ONLY AORTA & $6 / 22$ & 27.3 & $8 / 37$ & 21.6 & $2 / 7$ & 28.6 & 0.768 & 9 \\
\hline Intra-OP & $0 / 22$ & 0.0 & $3 / 37$ & 8.1 & $0 / 7$ & 0.0 & 0.679 & 20.1 \\
\hline $48 \mathrm{~h}$ post-OP & $4 / 22$ & 18.2 & $3 / 34$ & 8.8 & $1 / 7$ & 14.3 & 0.476 & 21.3 \\
\hline 30 days post-OP & $2 / 18$ & 11.1 & $2 / 31$ & 6.5 & $1 / 6$ & 16.6 & 0.508 & 8.4 \\
\hline In-Hospital & $0 / 16$ & 0.0 & $0 / 29$ & 0.0 & $0 / 5$ & 0.0 & 1.0 & - \\
\hline AORTA with add OP & $6 / 15$ & 40.0 & $11 / 33$ & 33.3 & $7 / 14$ & 50.0 & 0.520 & 10.8 \\
\hline Intra-OP & $1 / 15$ & 6.7 & $1 / 33$ & 3.1 & $2 / 14$ & 14.3 & 0.327 & 9.7 \\
\hline $48 \mathrm{~h}$ post-OP & $2 / 14$ & 14.3 & $6 / 32$ & 18.8 & $5 / 12$ & 41.6 & 0.240 & 20.6 \\
\hline 30 days post-OP & $1 / 12$ & 8.3 & $3 / 26$ & 11.5 & $0 / 7$ & 0.0 & 0.736 & 8.4 \\
\hline In-Hospital & $1 / 11$ & 9.1 & $1 / 23$ & 4.3 & $0 / 7$ & 0.0 & 0.675 & 12.3 \\
\hline
\end{tabular}

Whereas additional cardiac or aortic root surgery did not worsen post-operative survival, the extension of the aortic replacement influenced mortality. Hemiarch replacement was associated with lower mortality risk than total arch replacement (Table 12). Furthermore, the recent use of the Evita prosthesis seems to reduce the mortality in the entire arch replacement ACP subgroups, however without reaching the level of significance because of the low sample size. 
Table 12. Influence of type of operation on 30 days mortality

\begin{tabular}{|c|c|c|c|c|c|c|c|c|}
\hline \multirow[b]{2}{*}{ Total Patient Nr. } & \multicolumn{2}{|c|}{ DHCA } & \multicolumn{2}{|c|}{ ACP } & \multicolumn{2}{|c|}{ RCP } & \multirow{2}{*}{$\begin{array}{l}\mathbf{P} \\
-\end{array}$} & \multirow{2}{*}{$\begin{array}{c}1-\beta \\
\%\end{array}$} \\
\hline & 37 & $\%$ & 70 & $\%$ & 21 & $\%$ & & \\
\hline ONLY AORTA & $6 / 22$ & 27.3 & $8 / 37$ & 21.6 & $2 / 7$ & 28.6 & & \\
\hline Hemiarch Replacement & $2 / 5$ & 40.0 & $2 / 5$ & 40.0 & $0 / 0$ & 0.0 & 1.0 & - \\
\hline Total Arch Rep / FET & $4 / 17$ & 23.5 & $5 / 24$ & 20.8 & $2 / 7$ & 28.6 & 0.444 & 20.7 \\
\hline Evita-Open & $0 / 0$ & 0.0 & $1 / 8$ & 12.5 & $0 / 0$ & 0.0 & 1.0 & - \\
\hline AORTA with add OP & $6 / 15$ & 40.0 & $11 / 33$ & 33.3 & $7 / 14$ & 50.0 & & \\
\hline Hemiarch Replacement & $2 / 8$ & 25 & $2 / 12$ & 16.7 & $1 / 1$ & 100.0 & 0.321 & 7.2 \\
\hline Total Arch Rep / FET & $3 / 7$ & 42.9 & $9 / 18$ & 50.0 & $6 / 13$ & 46.2 & 0.912 & 4.2 \\
\hline Evita-Open & $0 / 0$ & 0.0 & $0 / 3$ & 0.0 & $0 / 0$ & 0.0 & 1.0 & - \\
\hline
\end{tabular}

\subsection{Relationship between Visceral Dysfunction and Mortality}

Further statistical analysis revealed that independently of the type of cerebral protection used, early increase in the GPT $(\mathrm{P}<0.05)$ is associated with mortality, whereas GGT remains similarly low in all patients during the first 5 post-operative days (Figure 16).

Similarly, both bilirubin and AP remain initially unchanged and begin to increase only after the first week of the post-operative period. Therefore these markers are rather useful in predicting only later risk for mortality (Figure 17). 
Figure 16. Hepatic function and mortality
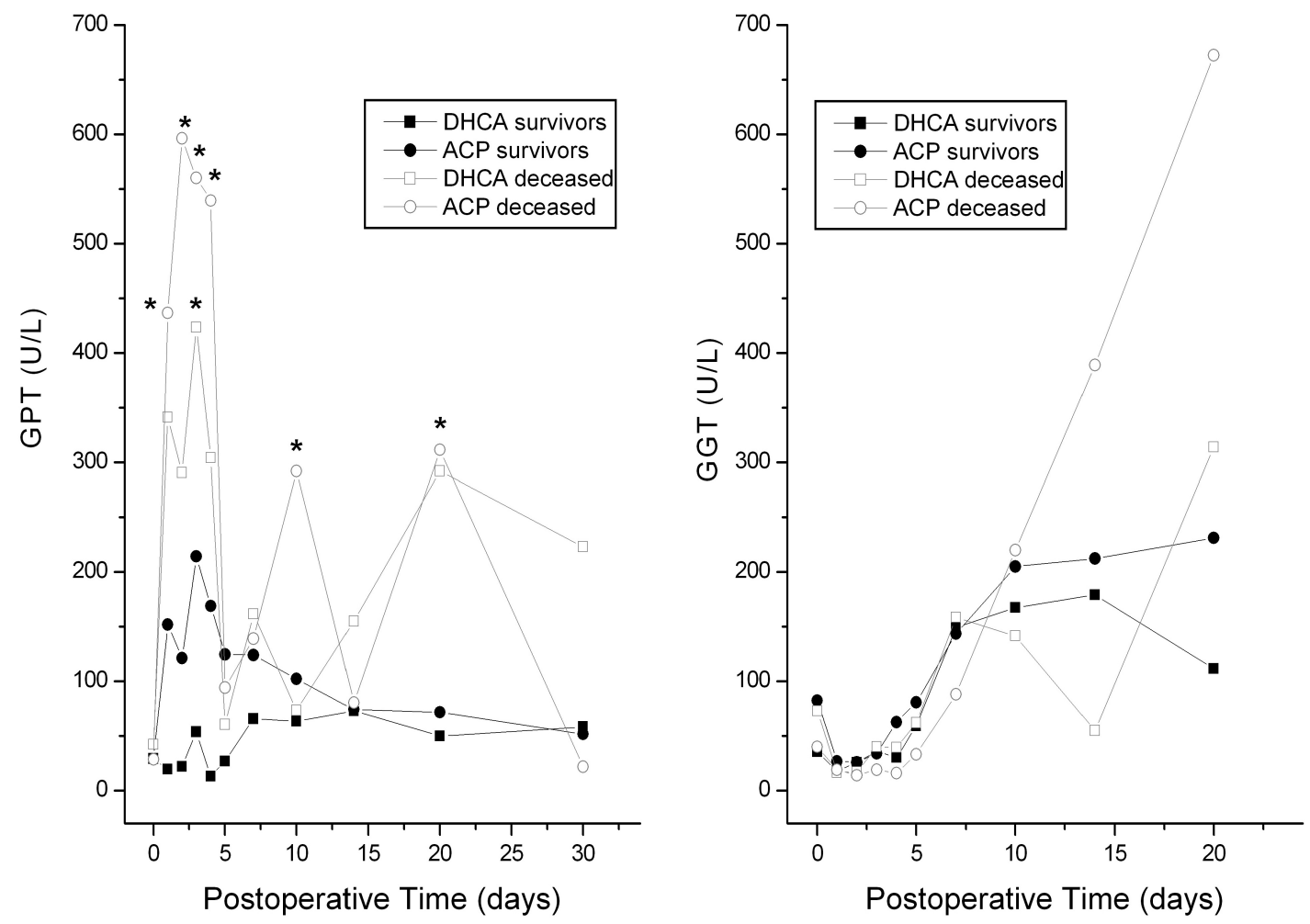

Figure 17. Gastrointestinal inflammation and mortality
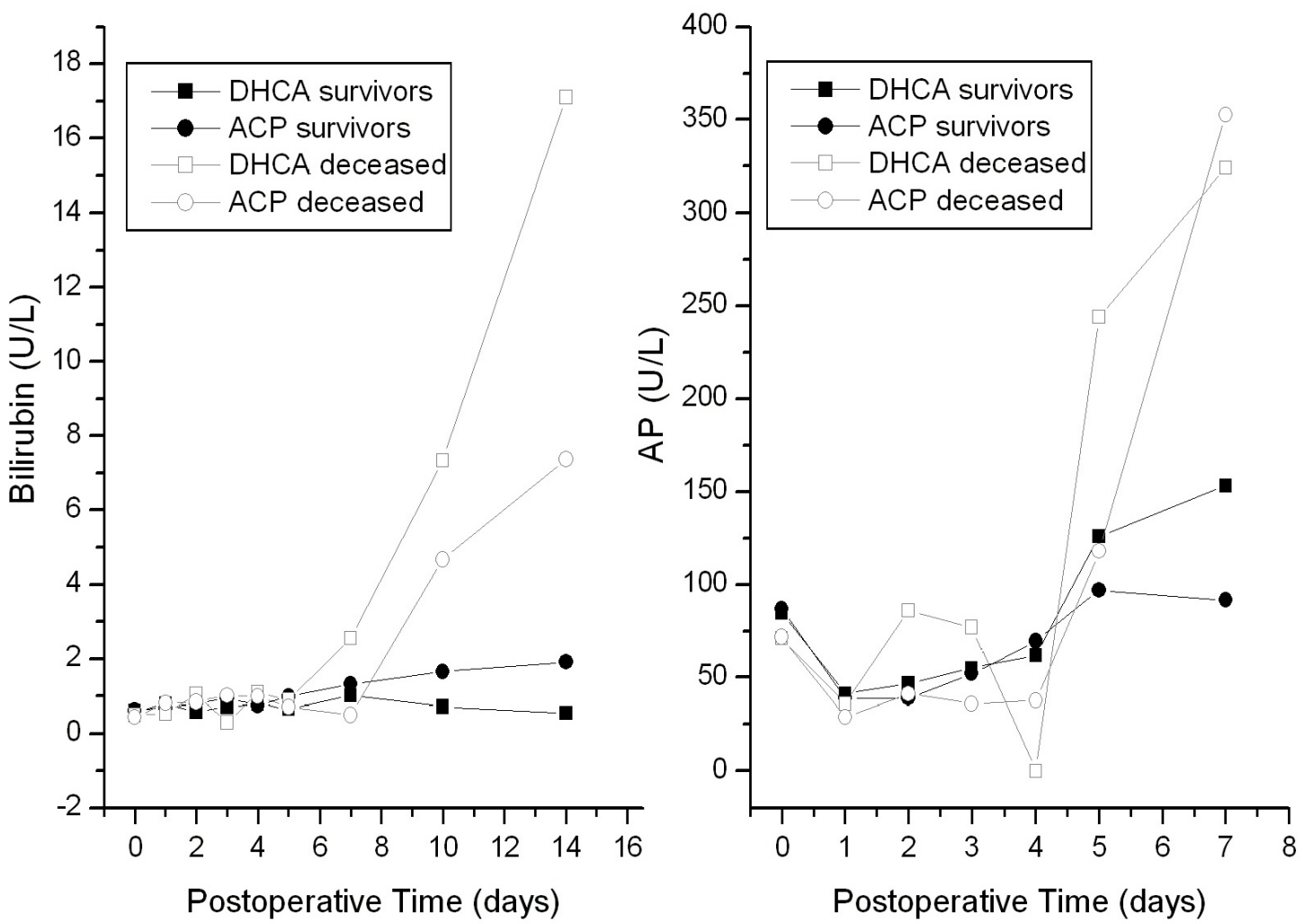

Mean values of laboratory parameters are represented. DHCA, deep hypothermic circulatory arrest survivors $(n=25)$ and non-survivors $(n=12)$; ACP, antegrade cerebral perfusion survivors $(n=51)$ and non-survivors $(\mathrm{n}=19) .{ }^{*}, \mathrm{P}<0.05$ deceased vs. survivors in the same cerebral protection group. 
Figure 18. Intestinal ischemia/reperfusion damage and mortality
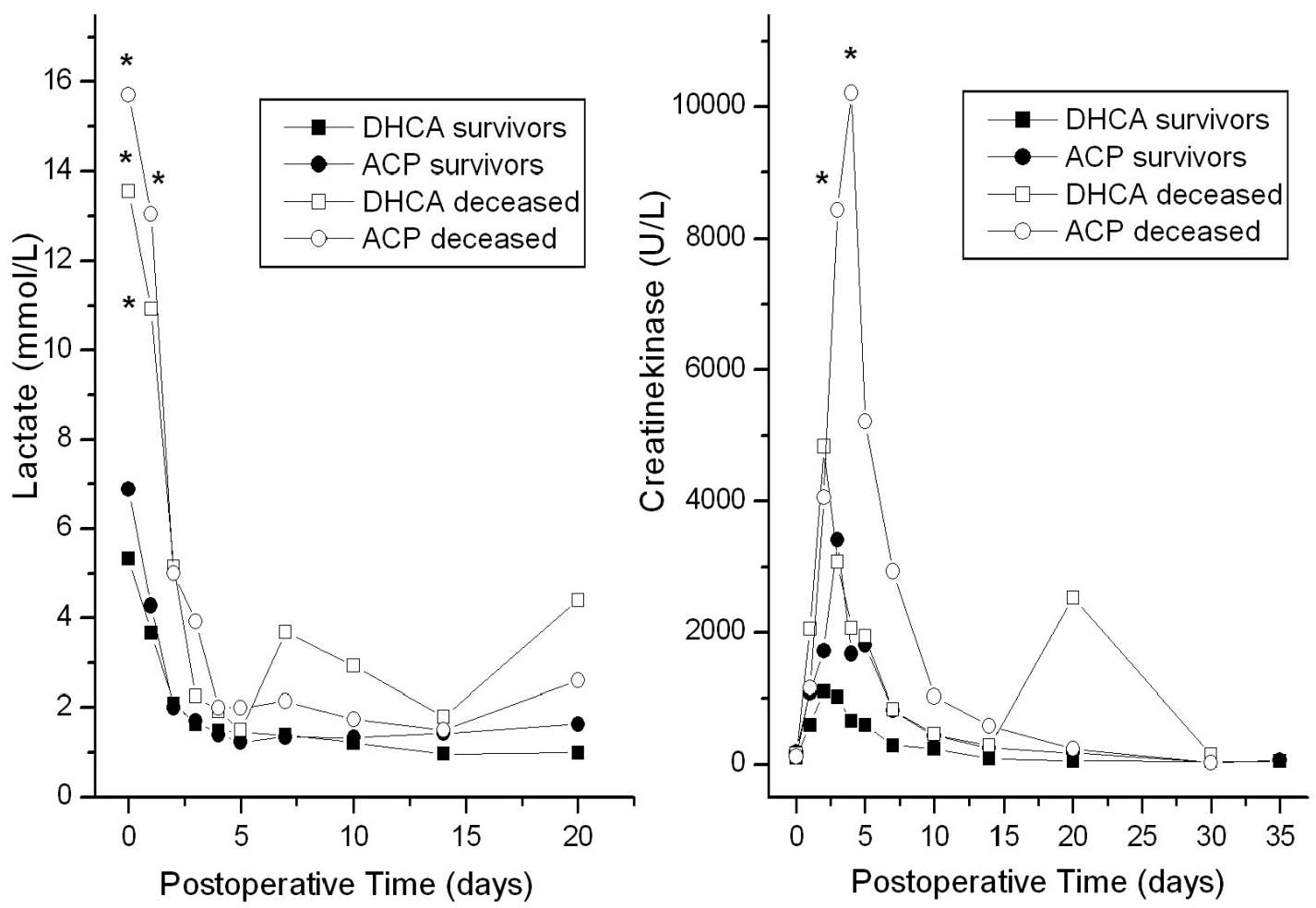

Figure 19. Renal function and mortality
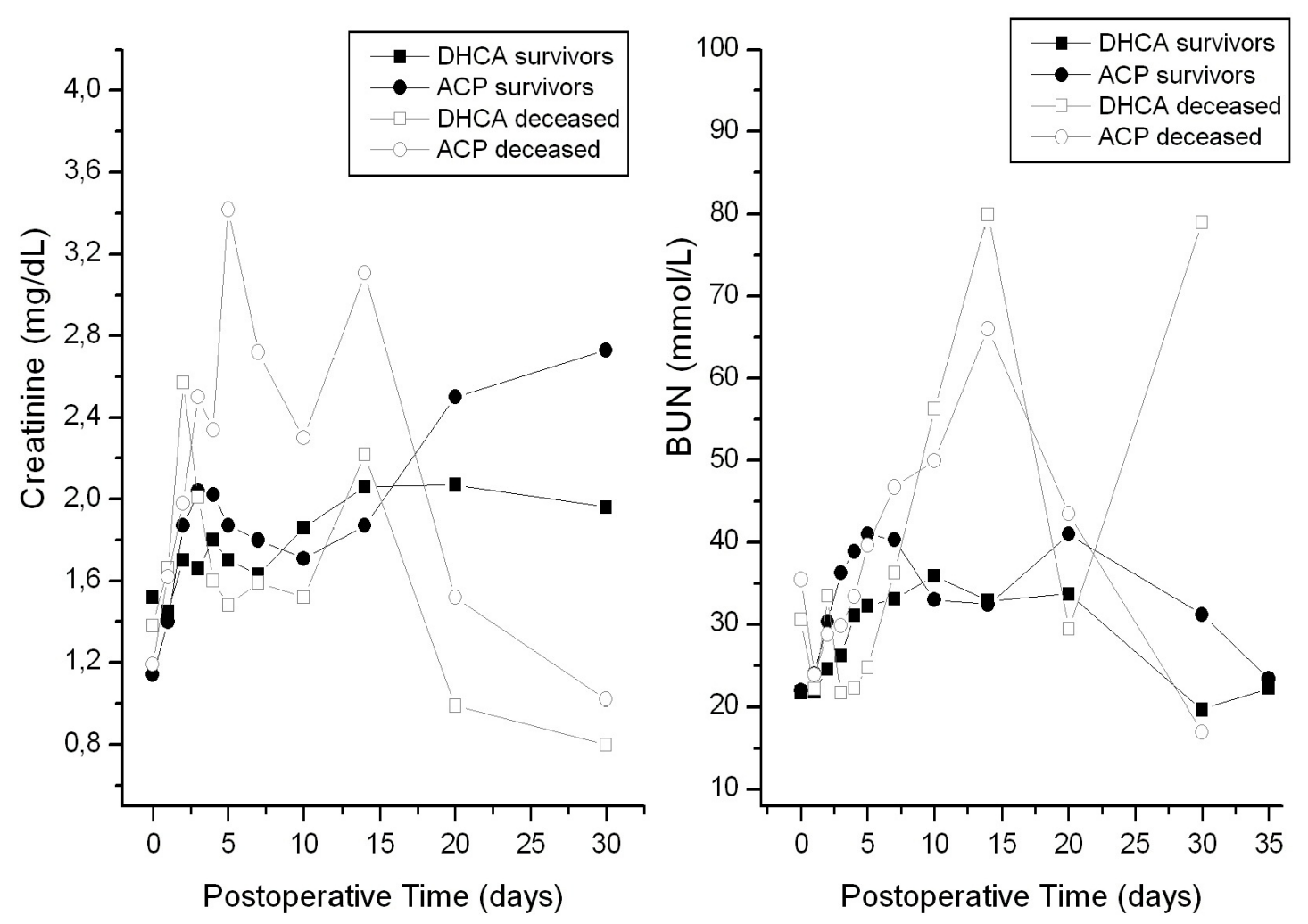

Mean values of laboratory parameters are represented. DHCA, deep hypothermic circulatory arrest survivors $(\mathrm{n}=25)$ and non-survivors $(\mathrm{n}=12) ; \mathrm{ACP}$, antegrade cerebral perfusion survivors $(\mathrm{n}=19)$ and non-survivors $(\mathrm{n}=51) . *, \mathrm{P}<0.05$ deceased vs. survivors in the same cerebral protection group. 
Lactate seems to be the most sensitive early marker of intestinal damage and mortality $(\mathrm{P}<$ 0.01) independently of the type of cerebral protection used. The early post-operative increase of the serum $\mathrm{CK}$ seems to be a relevant marker only for patients receiving antegrade cerebral perfusion $(\mathrm{P}<0.05)$ and remained rather insensitive when circulatory arrest is solely used (Figure 18).

Markers of renal function (Figure 19) change without showing any trend and without reaching the level of significance.

The analysis of the pre-operative markers reveals that lactate - as marker of already preoperatively present ischemia and hemodynamic instability- is a relevant predictor for early mortality in all groups independently of type of intra-operative perfusion used (Figure 20).

Figure 20. Relationship between pre-operative lactate values and mortality
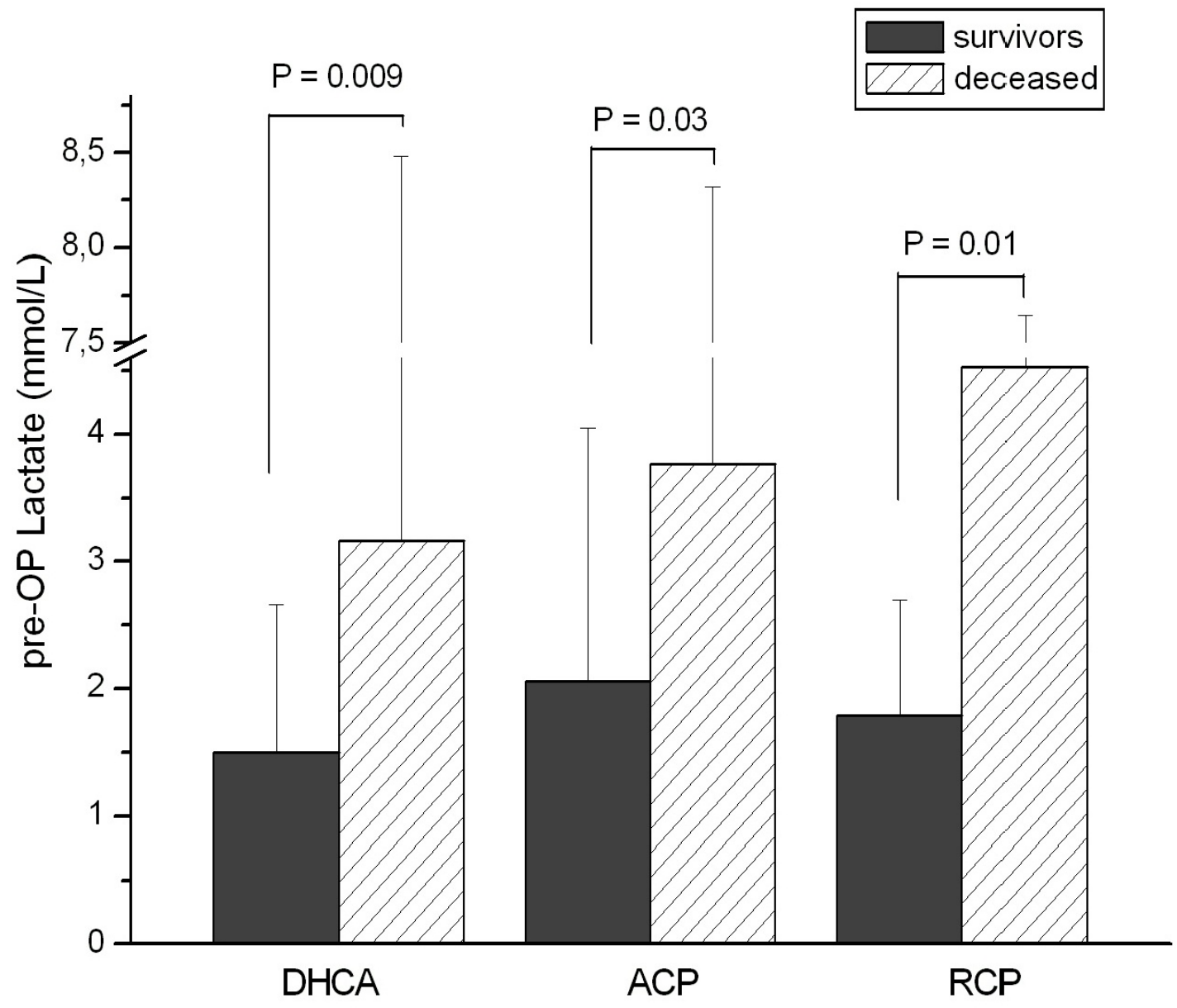


\section{Discussion}

Intra-operative splanchnic damage and intestinal barrier dysfunction are implicated as important triggering events in the development of post-operative multiorgan dysfunction. Transmural intestinal necrosis is the most deleterious form of intestinal damage and is related to significant mortality and morbidity mainly attributed to diagnostic delay (Acosta et al. 2006).

The early diagnosis of abdominal malperfusion remains difficult. To date, there is no systematic report on the incidence of non-occlusive splanchnic ischemia after aortic arch surgery, mainly due to the low rate of postmortem examinations and the cause of death stated as multi-organ failure.

To study visceral damage during aortic surgery with circulatory arrest, we analyzed conventional markers of hepatic, intestinal and renal damage in patients undergoing different cerebral protection techniques.

In this study, the three different protection and perfusion strategies used during surgical repair of the diseased aortic arch were associated with comparable survival at discharge (Table 11). Furthermore, no significant difference was found in the incidence of adverse operative outcome (Table 5, Table 9, Table 10). Thus, all three approaches could remain viable tools in similar patient populations.

The rates of early reoperation in our study (Table 5) were similar between the groups and are comparable to those reported in the contemporary era (Estrera et al. 2008; Milewski et al. 2010; Halkos et al. 2009) despite a high frequency of acute type A dissection $(>71 \%$, Table 3) and total arch repair (>64\%, Table 4) in our cohort. This could be explained by the similar extent of aortic repair (Table 4), which led to similar mean operative, ischemic, arrest and reperfusion times (Table 5). Moreover, the need for additional surgical procedures may have prolonged the cardiac arrest time and total operation time, however without influencing the circulatory arrest times (Figure 1).

Although variable additional surgeries have been necessary, the incidence of additional surgical procedures assessed in each subgroup was comparable between the groups (Table 4), allowing an objective comparative evaluation of visceral function based on the adjacent perfusion technique. 
Previous studies (Kawahito et al. 2003) showed that patients with acute coronary involvement during type A aortic dissection often underwent additional CABG procedure which was associated with a high risk of post-operative low cardiac output syndrome and in-hospital death. The present results cannot bring any new insights in this issue: although an assessment of the impact of additional CABG on post-operative cardiac function and visceral dysfunction was beyond the scope of the study, CABG resulted in comparable cardiac function during the post-operative period (Figure 7).

Nonetheless, whereas a lower proportion of patients required intra-operative catecholamine administration in the RCP group (Figure 2), a higher proportion of the patient receiving ACP or RCP required blood products (Figure 3). However, the amounts of catecholamine and blood products administered intra-operatively were similar in the three main groups (Figure 3, Figure 5) suggesting no superiority of one or another cerebral protection technique in terms of systemic homeostasis at the end of the operation (Table 6, Table 8). Similar requirements for buffer administration (Figure 2, Figure 3) might suggest that a correct hemodynamic and homeostatic equilibrium has been achieved in all patients.

Patient status at presentation represents an important predictive factor for the postoperative outcome and the pre-operative presence of mesenteric malperfusion is considered the most devastating condition (Totsugawa et al. 2010). Even more, Pacini et al. (2013) affirm that malperfusion of more organ systems before the operation makes immediate proximal aortic repair sub-optimal and the prognosis really unfavorable. Other studies (Wurm et al. 2017; Pang et al. 2012) revealed that lactate and base deficit at admission were associated with post-operative non-occlusive mesenteric ischemia after cardiac procedure under CPB without circulatory arrest. Takasu et al. (2007) demonstrated that base deficit at admission was associated with the duration of pre-operative cardiac resuscitation in hemodynamically instable patients, but not with mortality. In the present study, no significant differences in terms of blood gas analysis were assessed between the groups at the time of admission (Table 7), and this finding corresponds to the high percentage of hemodynamically stable patients identified in each group before the operation (Table 2), without any signs of intestinal ischemia.

Based on the results of Wurm et al. (2017), also seems that avoidance of hypoxia during the intensive care stay, that also characterizes the present findings, may prevent worst outcome of pre-existing non-occlusive mesenteric ischemia. The present study reveals that the first post-operative blood gas analysis (Table 8) showed similar values in the three main groups, reflecting a similar pharmacological and anesthesiological support during the operation. 
However, coagulation disorders at operation could be accentuated by longer CPB times (Hong et al. 2017). In this respect, the present findings unveiled no significant differences in the subgroups with and without additional surgical procedures during the post-operative period (Figure 9, Figure 10). These findings might support the importance of inflammatory and oxidative mechanisms in the development of post-operative complications after complex aortic surgery and less importance of the surgical trauma and CPB-associated hemolysis per se.

Similar continuation therapy during the intensive care stay is reflected by the findings presented in Table 9, Table 10 and Figure 7. No differences in terms of duration of ventilation, renal replacement therapy, catecholamine substitution and antibiotic therapy were found between the groups. However, an important finding of the present study is that cerebral perfusion during circulatory arrest - either antegrade or retrograde - was associated with a significant reduction in the catecholamine index during the post-operative period (Figure 8). This finding corresponds to the previous results of Algra et al. (2012a) who revealed lower catecholamine index values in newborn and pediatric patients receiving antegrade cerebral perfusion during aortic arch replacement.

In terms of pharmacological support with blood products and coagulation factors no significant differences between the groups have been observed during the intensive care stay (Figure 10, Figure 11). In this respect, Wurm et al. (2017) previously reported successful conservative treatment with erythrocyte concentrates and antibiotics for intestinal bleeding. The protective effect of supportive antibiotic treatment in the early stage of non-occlusive mesenteric ischemia was also suggested by Tendler (2003). It cannot be excluded that a similar mechanism could have offered a certain protection in our study as well.

Although blood gas analysis emphasized good homeostasis achieved at the discharge from operation theatre in all groups (Table 8), lactate values were significantly increased when other surgical procedures were additionally performed to the frozen elephant trunk or when RCP was used (Figure 9). All together, these findings might suggest that hemodynamic instability and the subsequent intensity of ischemia-reperfusion damage remain important causes of post-operative visceral dysfunction. However, Wurm et al. (2017) failed to observe a direct association between the duration of cardiopulmonary bypass and the occurrence of non-occlusive mesenteric ischemia.

Whereas contradictory results have been presented with respect to the impact of the length of cardiopulmonary bypass time on the mesenteric circulation, we agree with the idea that 
short times of hemodynamic instability are more relevant that the length of periods of stable mechanical support in influencing visceral function.

Experimental studies demonstrated that endothelial dysfunction is responsible for the postoperative intestinal malperfusion (Andrási et al. 2002; Andrási et al. 2003; Andrási et al. 2005). In the presence of pre-operative chronic low-cardiac output, smooth muscle cell injury additionally occurs in the mesentery after CPB. Accordingly, different vasoconstricting drugs given during resuscitation can influence systemic and mesenteric perfusion and oxygenation during the post-resuscitation period. Studer et al. (2002) assessed higher right atrial hemoglobin oxygen saturation and lower intestinal tonometric $\mathrm{pCO}_{2}$ and lactate levels after vasoconstrictor administration, and both lactate and creatine kinase demonstrated to be reliable early markers of mesenteric ischemia and reperfusion injury in an experimental setting (van der Voort et al. 2014). On the other side, therapeutic hypothermia increases the resistance of the intestine to ischemia-reperfusion injury (Albrecht et al. 2012).

Taken together, the occurrence of visceral injury seems to be multifactorial and is mostly influenced by a combination of acute ischemic injury during circulatory arrest in mild-tomoderate hypothermia, as well as pre- and post-operative hemodynamic fluctuations after dissection and extensive occlusion of the collateral pathways.

The present study reveals that markers of visceral function changed differently during the post-operative period. Whereas GPT increased during the first 5 to 10 post-operative days in the ACP and RCP groups, GGT remained unchanged at the beginning and increased in all groups after the $5^{\text {th }}$ post-operative days remaining higher up to the $30^{\text {th }}$ post-operative day (Figure 11). The markers of gastrointestinal inflammation (Figure 12) showed fewer changes during the 30 post-operative days than the hepatic markers, supporting a possible anti-inflammatory effect of the systemic deep hypothermia (Albrecht et al. 2012).

Leukocyte count remains an unspecific parameter for non-occlusive mesenteric ischemia. Previous studies (Schuetz et al. 2010) showed that leukocytes were similarly elevated for as long as seven days, in patients subjected to operations with cardiac arrest independently from the presence of infections.

Oppositely, from the two markers of intestinal ischemia/reperfusion injury presented in Figure 13, lactate showed high levels already before the operation and decreases abruptly after the aortic repair, whereas creatine kinase started to increase after the operation and continued to increase during the first 48 post-operative hours in all groups. These findings clearly demonstrate that the early ischemia/reperfusion injury during the surgical procedure 
causes an early intestinal damage that could generate remote effects and thus influence the function of the other abdominal organs.

Several possible mechanisms were shown to be responsible for the mesenteric ischemia after circulatory arrest. First, mesenteric injury caused pre-operatively by dissection and subsequent malperfusion can be easily exacerbated by reperfusion after aortic surgical repair under circulatory arrest, resulting in coagulopathy, organ dysfunction, and systemic metabolic abnormalities (Fernandes et al. 2012; Fernández Suárez et al. 2017). However, the present study revealed similar degree of abdominal aortic involvement in all groups.

Second, although epinephrine may induce more myocardial damage related to its betaadrenergic inotropic action and may increase the severity of postresuscitation myocardial dysfunction (Tang et al. 1995), the use of epinephrine in the present cohort is compliant with the results of previous studies demonstrating that epinephrine for resuscitation tends to be associated with higher resuscitation rates (Studer et al. 2002) and improved intestinal perfusion. On the other hand administration of vasopressin was shown to result in higher cardiac output, less regional mesenteric ischemia (by $\mathrm{pCO}_{2}$ gap) and lower lactate levels. In contrast, Prengel et al. (1998) demonstrated an increased cardiac depressant effect of vasopressin compared with epinephrine. These conflicting effects of vasopressin seem to be explained by the biphasic effect (initial strong vasoconstriction followed by vasodilatation) assessed on isolated human mesenteric arteries (Martinez et al. 1994). Moreover, vasopressin-induced mesenteric vasoconstriction (Iwao et al. 1996) might be accentuated by the increased levels of endogenous angiotensin during resuscitation (Reilly et al. 1992; Reilly and Bulkley 1993).

Third, intestinal ischemic injury leads to disruption of the gut mucosal barrier and prompt release of endotoxin into the portal circulation; subsequently, hepatic macrophages produce tumor necrosis factor, which is an important mediator of reperfusion injury (Caty et al. 1990). This mechanism explains the present findings revealing initial intestinal damage followed by later hepatic dysfunction. Hepatic dysfunction has been described also after cardiac arrest without circulatory arrest (Cerchiari et al. 1993) and was also shown to be associated with bacteriemia in the visceral post-resuscitation syndrome.

As the present results reveal, independently from the type of cerebral protection used, the mesenteric ischemia/reperfusion injury is the early phenomena that may be documented after the procedure. Oppositely, the abdominal markers of bowel inflammation, hepatic injury and kidney dysfunction remain unchanged up to the $5^{\text {th }}$ post-operative day in all 
groups. Moreover, the markers of kidney function (Figure 14, Figure 19) remain difficult to be interpreted because of the effect of renal replacement therapy.

Forth, a recent experimental study in a rat model (Karhausen et al. 2013) revealed that primary injury caused by deep hypothermic circulatory arrest in the intestine is an ischemia/reperfusion type injury and revealed for the first time the role of mast cells in the gut injury and systemic inflammatory responses. They emphasize that mast cells translate splanchnic microvascular hypoperfusion into an immune-inflammatory responses following cardiac surgery. Intestinal ischemia/reperfusion injury was also shown to be a primary event following rewarming after DHCA (Karhausen et al. 2013) and playing an important role in both, local and systemic inflammation.

Apart from these four pathological mechanisms, therapeutic hypothermia was shown to increase the resistance of the intestine to ischemia-reperfusion injury (Albrecht et al. 2012). Moreover, it seems that in hemodynamically stable patients, hypothermia remains the major protective tool of visceral organs also during circulatory arrest. In the adults, collateral perfusion offered by ACP did not significantly protect against post-operative visceral dysfunction. Previous studies have demonstrated that in neonates with congenital heart failure undergoing complex aortic arch repair (Algra et al. 2012a; Algra et al. 2012b), abdominal organs are better protected by low-flow ACP than by DHCA. These studies also indicated that increased DHCA duration adversely affects post-operative recovery, whereas even prolonged ACP is apparently without consequences (Algra et al. 2012a). However, in the case of aortic dissection - which is characteristic to the present adult cohort - no significant difference in the visceral function was assessed between the groups undergoing different type of cerebral protection.

Consistent with the similar modifications of visceral function in the present study, mortality did not differ significantly between the groups; although mortality tended to be higher in patients receiving additional operation or total arch replacement, this did not achieve the level of significance, probably due to the relatively small patient numbers documented in each subgroup (Table 11, Table 12).

Based on the present findings, we incline to believe that the pre-operative hemodynamic instability is playing a decisive role in the post-operative outcome.

Wurm and Zierer (Wurm et al. 2017; Zierer et al. 2007) found that patients who died of non-occlusive mesenteric after cardiac arrest had elevated lactate and greater base excess at admission than the survivors. Similarly, van Arsdell et al. (1998) noted in an autopsy series of acute type A aortic dissection that unoperated patients often had only one entry and 
reentry tear compared with patients operated on with aortic cross-clamping, who generally had multiple tears. Indeed, changes in the hepatic markers (Figure 16) and markers of intestinal inflammation (Figure 17) occurred at similar time-points in all patients in the present study, and these changes were more accentuated in the non-surviving patients than in survivors. In particular, the markers of intestinal ischemia/reperfusion injury showed significantly higher levels in the deceased patient group that in the survival group (Figure 18).

Moreover, the data of the present study confirm that pre-operative lactate values were significantly increase in each group of non-survivals (Figure 29), and the different types of cerebral protection methods that have been applied could not reduce the impact of preoperative status on mortality.

Therefore patient status at presentation represents an important predictive factor for postoperative outcome in patients receiving aortic arch replacement.

\subsection{Limitations}

Limitations of this study are due to the retrospective design and the heterogeneity of the cohort as well as to the small number of patients in the subgroup.

While some parameters were confirmed to be associated with visceral ischemia, caution should be applied when interpreting these results because of the small number of cases. The incidence rates might not be the same in other populations.

The markers of hepatic dysfunction (GPT, GGT), intestinal inflammation (Bilirubin, AP) and renal injury (Creatinine, BUN) were not significantly influence by the type of cerebral protection used. Although lactate and CK were the only markers associated with mortality in the present study, they are not solely associated with gastrointestinal dysfunction; therefore a cause-effect relationship between visceral injury and mortality after open surgical aortic arch replacement cannot be proven.

Since the cause of death was most often stated as apparent and part of post-dissection or post-circulatory arrest multi-organ failure, post-mortem exams were not routinely performed in this cohort; that limited the possibility of identifying the cases of nonocclusive mesenteric ischemia based on the pathological report. 


\subsection{Conclusion}

1. ACP and RCP offer no significant protection of abdominal viscera during circulatory arrest. Their principal benefit remains cerebral protection.

2. The parameters determined in the present study were in normal range in the early postoperative period in all groups. Differences occurred in the later post-operative period emphasizing that hypothermia offers similar visceral protection independently from the type of cerebral perfusion used. The later differences in biomarkers could be associated with the degree of true lumen opening and the subsequent degree of visceral perfusion.

3. GPT, Lactate and Creatine kinase seem to be sensitive markers of early visceral damage, whereas GGT, Bilirubin and AP were markers of delayed visceral dysfunction. Creatinine and BUN can be hardly interpreted because of the interference with renal replacement therapy during the early post-operative period.

4. Early increase in plasma lactate and CK are associated with increased mortality. 


\section{Summary}

The purpose of the current investigation was to determine how different approaches of cerebral protection (DHCA, ACP and RCP) influence abdominal organ function after open surgical aortic arch replacement and establish relationships to operative mortality, clinical outcome, and long-term survival.

Demographic data, pre-operative and operative characteristics as well as post-operative markers of visceral function were retrospectively analyzed in 128 patients with acquired aortic arch disease who underwent open surgical aortic arch replacement under DHCA, ACP or RCP between June 2005 and March 2016 at the Department of Thoracic, Cardiac and Vascular Surgery, University of Göttingen, Germany.

There were no significant differences between the three groups of patients in terms of demographic data, clinical status, disease extension, characteristics of the surgical techniques, operative times and need for revision. However, DHCA patients required significantly more catecholamine support during the post-operative period than ACP or RCP patients.

GPT, Lactate and Creatine kinase seem to be sensitive markers of early post-operative visceral damage whereas GGT, Bilirubin and AP are markers of delayed visceral dysfunction. Higher pre-operative lactate levels, as well as early post-operative increase in plasma lactate and CK were associated with mortality in all groups independently of type of intra-operative perfusion used.

Therefore, ACP and RCP offer no significant protection of abdominal viscera during circulatory arrest. Their main advantage seems to remain in the field of cerebral protection. The main protector of visceral organs seems to be deep hypothermia that was similarly applied in all three groups. 


\section{Zusammenfassung - Summary in German}

Zielsetzung der vorliegenden Arbeit war es zu bestimmen, inwieweit die verschiedenen Vorgehensweisen für die zerebrale Protektion (Kreislaufstillstand mit tiefer Hypothermie (DHCA), antegrade zerebrale Perfusion (ACP) und retrograde zerebrale Perfusion (RCP)) bei offen-chirurgischem Aortabogenersatz die Funktion der abdominalen Organe beeinflussen. Weiterhin sollten auf Basis geeigneter Parameter Beziehungen zu operativer Mortalität, klinischem Ergebnis und Langzeit-Resultaten etabliert werden.

Demographische Daten, prä-, intra- und post-operative Charakteristika sowie postoperative Marker der viszeralen Funktion wurden in einer retrospektiven Studie analysiert. Basis der Untersuchung waren 128 Patienten mit erworbener Erkrankung des Aortabogens, die sich im Zeitraum zwischen Juni 2005 und März 2016 einem offen-chirurgischen Aortabogenersatz unter Zuhilfenahme der zerebralen Protektionstechniken DHCA, ACP, RCP in der Klinik für Thorax-, Herz- und Gefäßchirurgie der Universität Göttingen, Deutschland, unterzogen haben.

Bezüglich der Parameter demographische Daten, klinischer Status, Ausdehnung der Erkrankung, Charakteristika der chirurgischen Techniken, OP-Zeiten und Notwendigkeit von Revisionen wiesen die drei untersuchten Gruppen keine signifikanten Unterschiede auf. Jedoch benötigten die Patienten der DHCA-Gruppe signifikant höhere Gaben an Katecholaminen während der post-operativen Phase als die Patienten der ACP- oder RCPGruppen.

Glutamat-Pyruvat-Transaminase, Laktate und Creatine kinase scheinen sensitive Marker für eine frühe post-operative viszerale Schädigung darzustellen, während Gamma-GlutamylTranspeptidase, Bilirubin und AP Marker einer verzögerten viszeralen Dysfunktion sind. Erhöhte präoperative Laktatwerte sowie ein früher post-operativer Anstieg der PlasmaLaktate und der Creatine kinase stehen in Verbindung mit Mortalität in allen Gruppen, unabhängig vom Typ der intra-operativ angewandten Perfusionsverfahren.

Deshalb bieten ACP und RCP keinen signifikant erhöhten Schutz der abdominalen viszeralen Organe während eines Kreislaufstillstands. Ihr Hauptvorteil scheint auf dem Bereich des zerebralen Schutzes zu liegen. Der bedeutendste Protektionsfaktor der viszeralen Organe bleibt wohl nach wie vor die tiefe Hypothermie, die in allen drei Gruppen in ähnlicher Weise zur Anwendung kam. 


\section{References}

Acosta S, Ogren M, Sternby NH, Bergqvist D, Björck M (2006): Fatal nonocclusive mesenteric ischaemia: population-based incidence and risk factors. J Intern Med 259, 30513

Algra SO, Kornmann VN, van der Tweel I, Schouten AN, Jansen NJ, Haas F (2012a): Increasing duration of circulatory arrest, but not antegrade cerebral perfusion, prolongs postoperative recovery after neonatal cardiac surgery. J Thorac Cardiovasc Surg 143 , 37582

Algra SO, Schouten AN, van Oeveren W, van der Tweel I, Schoof PH, Jansen NJ, Haas F (2012b): Low-flow antegrade cerebral perfusion attenuates early renal and intestinal injury during neonatal aortic arch reconstruction. J Thorac Cardiovasc Surg 144, 1323-8

Albrecht M, Gruenewald M, Zitta K, Zacharowski K, Scholz J, Bein B, Meybohm P (2012): Hypothermia and anesthetic post-conditioning influence the expression and activity of small intestinal proteins possibly involved in ischemia/reperfusion-mediated events following cardiopulmonary resuscitation. Resuscitation $\underline{83}, 113-8$

Andrási TB, Buhmann V, Soós P, Juhász-Nagy A, Szabó G (2002): Mesenteric complications after hypothermic cardiopulmonary bypass with cardiac arrest: underlying mechanisms. Artif Organs 26, 943-6

Andrási TB, Soós P, Bakos G, Stumpf N, Blazovics A, Hagl S, Szabó G (2003): L-arginine protects the mesenteric vascular circulation against cardiopulmonary bypass-induced vascular dysfunction. Surgery $134,72-9$

Andrási TB, Bielik H, Blázovics A, Zima E, Vágó H, Szabó G, Juhász-Nagy A (2005): Mesenteric vascular dysfunction after cardiopulmonary bypass with cardiac arrest is aggravated by coexistent heart failure. Shock 23 , 324-9 
Andrási TB, Mertens F, Barabás B, Blázovics A (2014): Effect of haemodynamic changes on epithelium-related intestinal injury in off pump coronary surgery. Heart Lung Circ $\underline{23}$, $144-51$

Andropoulos DB, Stayer SA, McKenzie ED, Fraser JNCD (2003): Cerebral physiologic monitoring to guide low-flow cerebral perfusion during neonatal aortic arch reconstruction. J Thorac Cardiovasc Surg $\underline{125}$, 491-9

Apaydin AZ, Buket S, Posacioglu H, Islamoglu F, Calkavur T, Yagdi T, Ozbaran M, Yuksel M (2002): Perioperative risk factors for mortality in patients with acute type A aortic dissection. Ann Thorac Surg 74, 2034-9

Askenazi DJ, Koralkar R, Levitan EB, Goldstein SL, Devarajan P, Khandrika S, Mehta RL, Ambalavanan N (2011): Baseline values of candidate urine acute kidney injury (AKI) biomarkers vary by gestational age in premature infants. Pediatr Res $\underline{70}, 302-6$

Bachet J, Guilmet D, Goudot B, Termignon JL, Teodori G, Dreyfus G, Brodaty D, Dubois C, Delentdecker P (1991): Cold cerebroplegia. A new technique of cerebral protection during operations on the transverse aortic arch. J Thorac Cardiovasc Surg 102, 85-93

Bachet JE: Distal anastomosis first. In: Coselli JS, LeMaire SA (eds.): Aortic Arch Surgery: Principles, Stategies and Outcomes. Blackwell Publishing, Oxford 2008, 187-98

Baumgartner WA, Redmond M, Brock M, Tseng E, Blue ME, Troncoso JC, Johnston MV (1997): Pathophysiology of cerebral injury and future management. J Card Surg 12, 300-10

Bavaria JE, Pochettino A, Brinster DR, Gorman RC, McGarvey ML, Gorman JH, Escherich A, Gardner TJ (2001): New paradigms and improved results for the surgical treatment of acute type A dissection. Ann Surg 234, 336-42

Bonser RS, Harrington DK: Retrograde cerebral perfusion. In: Coselli JS, LeMaire SA (eds.): Aortic Arch Surgery: Principles, Stategies and Outcomes. Blackwell Publishing, Oxford 2008, 167-74 
Bonser RS, Ranasinghe AM, Loubani M, Evans JD, Thalji NM, Bachet JE, Carrel TP, Czerny M, Di Bartolomeo R, Grabenwöger M, Lonn L, Mestres CA, Schepens MA, Weigang E (2011): Evidence, lack of evidence, controversy, and debate in the provision and performance of the surgery of acute type A aortic dissection. J Am Coll Cardiol $\underline{58}, 2455-74$

Borst HG, Frank G, Schaps DJ (1988): Treatment of extensive aortic aneurysms by a new multiple stage approach. Thorac Cardiovasc Surg 모, 11-3

Caty MG, Guice KS, Oldham KT, Remick DG, Kunkel SI (1990): Evidence for tumor necrosis factor-induced pulmonary microvascular injury after intestinal ischemiareperfusion injury. Ann Surg 212, 694-700

Cerchiari EL, Safar P, Klein E, Diven W (1993): Visceral, hematologic and bacteriologic changes and neurologic outcome after cardiac arrest in dogs. The visceral post-resuscitation syndrome. Resuscitation 25, 119-36

Chen JS, Ko WJ, Yu HY, Lai LP, Huang SC, Chi NH, Tsai CH, Wang SS, Lin FY, Chen YS (2006): Analysis of the outcome for patients experiencing myocardial infarction and cardiopulmonary resuscitation refractory to conventional therapies necessitating extracorporeal life support rescue. Crit Care Med $\underline{34}, 950-57$

Chiu P, Miller DC (2016): Evolution of surgical therapy for Stanford acute type A aortic dissection. Ann Cardiothorac Surg $\underline{5}, 275-95$

Crawford ES, Saleh SA (1981): Transverse aortic arch aneurysm: improved results of treatment employing new modifications of aortic reconstruction and hypothermic circulatory arrest. Ann Surg $\underline{194}, 180-8$

Danner BC, Natour E, Horst M, Dikov V, Ghosh PK, Dapunt OE (2007): Comparison of operative techniques in acute type A aortic dissection performing the distal anastomosis. J Card Surg 22, 105-10

Derikx JP, Evennett NJ, Degraeuwe PL, Mulder TL, van Bijnen AA, van Heurn LW, Buurman WA, Heineman E (2007): Urine based detection of intestinal mucosal cell 
damage in neonates with suspected necrotising enterocolitis. Gut $\underline{56}, 1473-5$

Di Eusanio M, Schepens MA, Morshuis WJ, Di Bartolomeo R, Pierangeli A, Dossche KM (2002): Antegrade selective cerebral perfusion during operations on the thoracic aorta: factors influencing survival and neurologic outcome in 413 patients. J Thorac Cardiovasc Surg 124, 1080-6

Di Eusanio M, Wesselink RM, Morshuis WJ, Dossche KM, Schepens MA (2003): Deep hypothermic circulatory arrest and antegrade selective cerebral perfusion during ascending aorta-hemiarch replacement: a retrospective comparative study. J Thorac Cardiovasc Surg $\underline{125}, 849-54$

Dong GH, Wang CT, Li Y, Xu B, Qian JJ, Wu HW, Jing H (2009): Cardiopulmonary bypass induced microcirculatory injury of the small bowel in rats. World J Gastroenterol $\underline{15}, 3166-72$

Dossche KM, Morshuis WJ, Schepens MA, Waanders FG (2000): Bilateral antegrade selective cerebral perfusion during surgery on the proximal thoracic aorta. Eur J Cardiothorac Surg 17, 462-7

Du Y, Zappitelli M, Mian A, Bennett M, Ma Q, Devarajan P, Mehta R, Goldstein SL (2011): Urinary biomarkers to detect acute kidney injury in the pediatric emergency center. Pediatr Nephrol 26, 267-74

Ehrlich MP, Ergin MA, McCullough JN, Lansman SL, Galla JD, Bodian CA, Apaydin AZ, Griepp RB (2000): Predictors of adverse outcome and transient neurological dysfunction after ascending aorta/hemiarch replacement. Ann Thorac Surg $\underline{69}, 1755-63$

Elefteriades JA (2010): What is the best method for brain protection in surgery of the aortic arch? Straight DHCA. Cardiol Clin $\underline{28}, 381-7$

Estrera AL, Miller 3rd CC, Lee TY, Shah P, Safi HJ (2008): Ascending and transverse aortic arch repair; the impact of antegrade cerebral perfusion. Circulation $\underline{118}$, 160-6 
Etz CD, Plestis KA, Kari FA, Silovitz D, Bodian CA, Spielvogel D, Griepp RB (2008): Axillary cannulation significantly improves survival and neurologic outcome after atherosclerotic aneurysm repair of the aortic root and ascending aorta. Ann Thorac Surg $\underline{86}, 441-7$

Fann JI, Sarris GE, Mitchell RS, Shumway NE, Stinson EB, Oyer PE, Miller DC (1990): Treatment of patients with aortic dissection presenting with peripheral vascular complications. Ann Surg 212, 705-13

Fernandes P, Cleland A, Adams C, Chu MW (2012): Clinical and biochemical outcomes for additive mesenteric and lower body perfusion during hypothermic circulatory arrest for complex total aortic arch replacement surgery. Perfusion 27, 493-501

Fernández Suárez FE, Fernández Del Valle D, González Alvarez A, Pérez-Lozano B (2017): Intraoperative care for aortic surgery using circulatory arrest. J Thorac Dis $\underline{9}$, 50820

Geirsson A, Szeto WY, Pochettino A, McGarvey ML, Keane MG, Woo YJ, Augoustides JG, Bavaria JE (2007): Significance of malperfusion syndromes prior to contemporary surgical repair for acute type A dissection: outcomes and need for additional

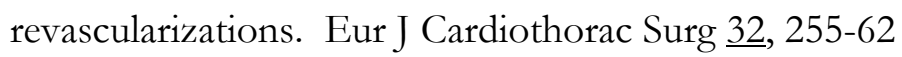

Girdauskas E, Kuntze T, Borger MA, Falk V, Mohr FW (2009): Surgical risk of preoperative malperfusion in acute type A aortic dissection. J Thorac Cardiovasc Surg 138 , 1363-9

Goldstein LJ, Davies RR, Rizzo JA, Davila JJ, Cooperberg MR, Shaw RK, Kopf GS, Elefteriades JA (2001): Stroke in surgery of the thoracic aorta: incidence, impact, etiology, and prevention. J Thorac Cardiovasc Surg 122, 935-45

Griepp RB, Stinson EB, Hollingsworth JF, Buehler D (1975): Prosthetic replacement of the aortic arch. J Thorac Cardiovasc Surg 70, 1051-63

Hagl C, Ergin MA, Galla JD, Lansman SL, McCullough JN, Spielvogel D, Sfeir P, Bodian CA, Griepp RB (2001): Neurologic outcome after ascending aorta-aortic arch operations: 
effect of brain protection technique in high-risk patients. J Thorac Cardiovasc Surg 121, $1107-21$

Halkos ME, Kerendi F, Myung R, Kilgo P, Puskas JD, Chen EP (2009): Selective antegrade cerebral perfusion via right axillary artery cannulation reduces morbidity and mortality after proximal aortic surgery J Thorac Cardiovasc Surg 138, 1081-9

Hong Liu, Qian Chang, Hai'Tao Zhang, CunTao Yu (2017): Predictors of adverse outcome and transient neurological dysfunction following aortic arch replacement in 626 consecutive patients in China. Heart, Lung and Circulation 26, 172-8

Immer FF, Grobety V, Lauten A, Carrel TP (2006): Does malperfusion syndrome affect early and mid-term outcome in patients suffering from acute type A aortic dissection? Interact CardioVasc Thorac Surg $\underline{5}, 187-90$

Iwao T, Toyonaga A, Oho K, Shigemori H, Sakai T, Tayama C, Masumoto H, Sato M, Tanikawa K (1996): Effect of vasopressin on esophageal varices blood flow in patients with cirrhosis: comparisons with the effects on portal vein and superior mesenteric artery blood flow. J Hepatol 25, 491-7

Karck M, Chavan A, Hagl C, Friedrich H, Galanski M, Haverich A (2003): The frozen elephant trunk technique: a new treatment for thoracic aortic aneurysms. J Thorac Cardiovasc Surg $\underline{125}, 1550-3$

Karhausen J, Qing M, Gibson A, Moeser AJ, Griefingholt H, Hale LP, Abraham SN, Mackensen GB (2013):Intestinal mast cells mediate gut injury and systemic inflammation in a rat model of deep hypothermic circulatory arrest. Crit Care Med $\underline{41}, 200-10$

Kato M, Ohnishi K, Kaneko M, Ueda T, Kishi D, Mizushima T, Matsuda H (1996): New graft-implanting method for thoracic aortic aneurysm or dissection with a stented graft. Circulation 노, II 188-93

Kawahito K, Adachi H, Murata S, Yamaguchi A, and Ino T (2003): Coronary malperfusion due to type A aortic dissection: mechanism and surgical management. Ann Thorac $\operatorname{Surg} \underline{76}, 1471-6$ 
Kazui T (2001): Simple and safe cannulation technique for antegrade selective cerebral perfusion. Ann Thorac Cardiovasc Surg $7,186-8$

Kazui T, Washiyama N, Muhammad BA, Terada H, Yamashita K, Takinami M (2001): Improved results of atherosclerotic arch aneurysm operations with a refined technique. $\mathrm{J}$ Thorac Cardiovasc Surg 121, 491-9

Kieffer E, Koskas F, Godet G, Bertrand M, Bahnini A, Benhamou AC, Cluzel P, Eyraud D (2000): Treatment of aortic arch dissection using the elephant trunk technique. Ann Vasc Surg 14, 612-9

Kouchoukos NT, Masetti P, Rokkas CK, Murphy SF (2001): Single stage reoperative repair of chronic type A aortic dissection by means of the arch-first technique. J Thorac Cardiovasc Surg 122, 578-82

Krawczeski CD, Woo JG, Wang Y, Bennett MR, Ma Q, Devarajan P (2011): Neutrophil gelatinase-associated lipocalin concentrations predict development of acute kidney injury in neonates and children after cardiopulmonary bypass. J Pediatr 158, 1009-15

Lai DT, Robbins RC, Mitchell RS, Moore KA, Oyer PE, Shumway NE, Reitz BA, Miller DC (2002): Does profound hypothermic circulatory arrest improve survival in patients with acute type a aortic dissection? Circulation 106, I218-28

Lemole GM (1995): Operation for type A aortic dissection. Ann Thorac Surg 60, 1863-4

Lemole GM, Strong MD, Spagna PM, Karmilowicz NP (1982): Improved results for dissecting aneurysms. Intraluminal sutureless prosthesis. J Thorac Cardiovasc Surg $\underline{83}$, 24955

Lewis FJ, Taufic M (1953): Closure of atrial septal defects with the aid of hypothermia; experimental accomplishments and the report of one successful case. Surgery $\underline{33}, 52-9$ Liang XL, Liu SX, Chen YH, Yan LJ, Li H, Xuan HJ, Liang YZ, Shi W (2010): Combination of urinary kidney injury molecule-1 and interleukin-18 as early biomarker for the diagnosis and progressive assessment of acute kidney injury following cardiopulmonary bypass surgery: a prospective nested case-control study. Biomarkers $\underline{15}$, 332-9 
Ly M, Roubertie F, Belli E, Grollmuss O, Bui MT, Roussin R, Lebret E, Capderou A, Serraf A (2011): Continuous cerebral perfusion for aortic arch repair: hypothermia versus normothermia. Ann Thorac Surg 92, 942-8

Martinez MC, Vila JM, Aldasoro M, Medina P, Flor B, Lluch S (1994): Relaxation of human isolated mesenteric arteries by vasopressin and desmopressin. Br J Pharmacol 113, $419-24$

Matsumura JS, Lee WA, Mitchell RS, Farber MA, Murad MH, Lumsden AB, Greenberg RK, Safi HJ, Fairman RM (2009): The Society for Vascular Surgery Practice Guidelines: management of the left subclavian artery with thoracic endovascular aortic repair. Society for Vascular Surgery. J Vasc Surg $\underline{50,1155-8}$

Milewski RK, Pacini D, Moser GW, Moeller P, Cowie D, Szeto WY, Woo YJ, Desai N, Di Marco L, Pochettino A, Di Bartolomeo R, Bavaria JE (2010): Retrograde and antegrade cerebral perfusion: results in short elective arch reconstructive times. Ann Thorac Surg 89, 1448-57

Mills N, Ochsner JL (1980): Massive air embolism during cardiopulmonary bypass. Causes, prevention, and management. J Thorac Cardiovasc Surg 무, 708-17

Miyaji K, Miyamoto T, Kohira S, Itatani K, Tomoyasu T, Inoue N, Ohara K (2010): Regional high-flow cerebral perfusion improves both cerebral and somatic tissue oxygenation in aortic arch repair. Ann Thorac Surg 무, 593-9

Moon MR, Sundt 3rd TM (2002a): Aortic arch aneurysms. Coron Artery Dis $\underline{13}$, 85-92

Moon MR, Sundt 3rd TM (2002b): Influence of retrograde cerebral perfusion during aortic arch procedures. Ann Thorac Surg 74, 426-31

Okita Y, Minatoya K, Tagusari O et al. (2001): Prospective comparative study of brain protection in total aortic arch replacement: deep hypothermic circulatory arrest with retrograde cerebral perfusion or selective antegrade cerebral perfusion. Ann Thorac Surg $\underline{72}, 72-9$ 
Oudemans-van Straaten HM, Jansen PG, Hoek FJ, van Deventer SJ, Sturk A, Stoutenbeek CP, Tytgat GN, Wildevuur CR, Eysman L (1996): Intestinal permeability, circulating endotoxin, and postoperative systemic responses in cardiac surgery patients. J Cardiothorac Vasc Anesth 10, 187-94

Pacini D, Leone A, Belotti LM, Fortuna D, Gabbieri D, Zussa C, Contini A, Di Bartolomeo R; RERIC (Emilia Romagna Cardiac Surgery Registry) Investigators (2013): Acute type A aortic dissection: significance of multiorgan malperfusion. Eur J Cardiothorac Surg $\underline{43}, 820-6$

Pang PY, Sin YK, Lim CH, Su JW, Chua YL (2012): Outcome and survival analysis of intestinal ischaemia following cardiac surgery. Interact Cardiovasc Thorac Surg 15, 215-8

Patel HJ, Williams DM, Dasika NL, Suzuki Y, Deeb GM (2008): Operative delay for peripheral malperfusion syndrome in acute type A aortic dissection: a long-term analysis. J Thorac Cardiovasc Surg 135, 1288-95

Pigula FA, Nemoto EM, Griffith BP, Siewers RD (2000): Regional low-flow perfusion provides cerebral circulatory support during neonatal aortic arch reconstruction. J Thorac Cardiovasc Surg $\underline{119}, 331-9$

Pigula FA, Gandhi SK, Siewers RD, Davis PJ, Webber SA, Nemoto EM (2001): Regional low-flow perfusion provides somatic circulatory support during neonatal aortic arch surgery. Ann Thorac Surg $\underline{72}$, 401-6

Prengel AW, Lindner KH, Wenzel V, Tugtekin I, Anhaupl T (1998): Splanchnic and renal blood flow after cardiopulmonary resuscitation with adrenaline/epinephrine and vasopressin in pigs. Resuscitation $\underline{38}, 19-24$

Reich DL, Uysal S, Sliwinski M, Ergin MA, Kahn RA, Konstadt SN, McCullough J, Hibbard MR, Gordon WA, Griepp RB (1999): Neuropsychologic outcome after deep hypothermic circulatory arrest in adults. J Thorac Cardiovasc Surg. 117, 156-63

Reilly PM, Bulkley GB (1993): Vasoactive mediators and splanchnic perfusion. Crit Care Med 21, 55-68 
Reilly PM, MacGowan S, Miyachi M, Schiller HJ, Vickers S, Bulkley GB (1992): Mesenteric vasoconstriction in cardiogenic shock in pigs. Gastroenterology 102, 1968-79

Sakurada T, Kazui T, Tanaka H, Komatsu S (1996): Comparative experimental study of cerebral protection during aortic arch reconstruction. Ann Thorac Surg $\underline{61}, 1348-54$

Sanioglu S, Sokullu O, Ozay B, Gullu AU, Sargin M, Albeyoglu S, Ozgen A, Bilgen F (2008): Safety of unilateral antegrade cerebral perfusion at 22 degrees C systemic hypothermia. Heart Surg Forum 11, E184-E18

Schepens MA, Dossche KM, Morshuis WJ, van den Barselaar PJ, Heijmen RH, Vermeulen FE (2002): The Elephanttrunk technique: operative results in 100 consecutive patients. Eur J Cardiothorac Surg 21, 276-81

Schuetz P, Affolter B, Hunziker S, Winterhalder C, Fischer M, Balestra GM, Hunziker P, Marsch S (2010): Serum procalcitonin, C-reactive protein and white blood cell levels following hypothermia after cardiac arrest: A retrospective cohort study. Eur J Clin Invest 40, 376-81

Sevransky J (2009): Clinical assessment of hemodynamically unstable patients. Curr Opin Crit Care $\underline{15}, 234-8$

Svensson LG, Crawford ES, Hess KR, Coselli JS, Raskin S, Shenaq SA, Safi HJ (1993): Deep hypothermia with circulatory arrest: Determinants of stroke and early mortality in 656 patients. J Thorac Cardiovasc Surg 106, 19-28

Strauch JT, Spielvogel D, Lauten A, Lansman SL, McMurtry K, Bodian CA, Griepp RB (2004): Axillary artery cannulation: routine use in ascending aorta and aortic arch replacement. Ann Thorac Surg 78, 103-8

Studer W, Wu X, Siegemund M, Seeberger M (2002): Resuscitation from cardiac arrest with adrenaline/epinephrine or vasopressin: effects on intestinal mucosal tonometer $\mathrm{pCO}_{2}$ during the postresuscitation period in rats. Resuscitation $\underline{53}, 201-7$ 
Takasu A, Sakamoto T and Okada Y (2007): Arterial base excess after CPR: The relationship to CPR duration and the characteristics related to outcome. Resuscitation $\underline{73}$, 394-9

Tang W, Weil MH, Sun S, Noc M, Yang L, Gazmuri RJ (1995): Adrenaline/epinephrine increases the severity of postresuscitation myocardial dysfunction. Circulation $\underline{92}$, 3089-93

Tchervenkov CI, Korkola SJ, Shum-Tim D, Calaritis C, Laliberté E, Reyes TU, Lavoie J (2001): Neonatal aortic arch reconstruction avoiding circulatory arrest and direct arch vessel cannulation. Ann Thorac Surg $\underline{72}, 1615-20$

Tendler DA (2003): Acute intestinal ischemia and infarction. Semin Gastrointest Dis $\underline{14}$, 66-76

Thuijls G, van Wijck K, Grootjans J, Derikx JP, van Bijnen AA, Heineman E, Dejong CH, Buurman WA, Poeze M (2011): Early diagnosis of intestinal ischemia using urinary and plasma fatty acid binding proteins. Ann Surg 253, 303-8

Tominaga R: Alternative approaches: The proximal first technique. In: Coselli JS, LeMaire SA (eds.): Aortic Arch Surgery: Principles, Stategies and Outcomes. Blackwell Publishing, Oxford 2008, 208-15

Tominaga R, Kurisu K, Ochiai Y, Hisahara M, Tanaka K, Onzuka T (2002): Early proximal aortic perfusion in total arch replacement. Jpn J Vasc Surg 11, 511-516

Totsugawa T, Ozawa M, Kuinose M, Ishii S, Yoshitaka H, Tamaki T (2010): Intraoperative endotoxin adsorption for visceral malperfusion complicating acute type A aortic dissection. Gen Thorac Cardiovasc Surg $\underline{58}, 134-7$

Tseng EE, Brock MV, Lange MS, Troncoso JC, Lowenstein CJ, Blue ME, Johnston MV, Baumgartner WA (1999): Nitric oxide mediates neurologic injury after hypothermic circulatory arrest. Ann Thorac Surg $\underline{67}, 65-71$

Tsunooka N, Maeyama K, Nakagawa H, Doi T, Horiuchi A, Miyauchi K, Watanabe Y, 
Imagawa H, Kawachi K (2006): Localization and changes of diamine oxidase during cardiopulmonary bypass in rabbits. J Surg Res 131, 58-63

Urbanski PP, Lenos A, Bougioukakis P (2012): Mild-to-moderate hypothermia in aortic arch surgery using circulatory arrest: a change of paradigm? Eur J Cardiothorac Surg $\underline{41}$, $185-91$

Van Arsdell GS, David TE, Butany J (1998): Autopsies in acute type A aortic dissection: Surgical implications. Circulation $\underline{98}$, II299-II302

Van der Voort PH, Westra B, Wester JP, Bosman RJ, van Stijn I, Haagen IA, Loupatty FJ, Rijkenberg S (2014): Can serum L-lactate, D-lactate, creatine kinase and I-FABP be used as diagnostic markers in critically ill patients suspected for bowel ischemia. BMC Anesthesiol $\underline{14}, 111$

Waikar SS, Sabbisetti VS, Bonventre JV (2010): Normalization of urinary biomarkers to creatinine during changes in glomerular filtration rate. Kidney Int $\underline{78}$, 486-494

Wurm R, Cho A, Arfsten H, van Tulder R, Wallmüller C, Steininger P, Sterz F, Tendl K, Balassy C, Distelmaier K, Hülsmann M, Heinz G, Adlbrecht C (2017): Non-occlusive mesenteric ischaemia in out of hospital cardiac arrest survivors. Eur Heart J Acute Cardiovasc Care 1, 2048872616687096

Zierer A, Moon MR, Melby SJ, Moazami N, Lawton JS, Kouchoukos NT, Pasque MK, Damiano RJ Jr (2007): Impact of perfusion strategy on neurologic recovery in acute type A aortic dissection. Ann Thorac Surg $\underline{83}, 2122-8$ 


\section{Acknowledgments}

At the end of my thesis I would like to thank all those people who made this thesis possible and an unforgettable experience for me.

First of all, I would like thank Professor Dr. med. Ingo Kutschka and Professor Dr. Dipl.Phys. Friedrich A. Schöndube for giving me opportunity to perform this research work at the Department of Thoracic, Cardiac and Vascular Surgery of the University of Göttingen.

My sincere gratitude goes to my advisor, PD Dr. med. Terézia Andrási-Wensauer, PhD for putting together the research project, for the continuous guidance and support during the extensive data acquisition, for explaining me the methodology of the related research and the individual characteristics of the surgical procedures, for her patience, motivation and immense scientific knowledge. Her guidance helped me during the entire research period and during the writing of this thesis. I could not have imagined having a better advisor and mentor for my dissertation.

I would also like to thank Professor Dr. med. Bernd Danner and Professor Dr. med. Anselm Bräuer not only for their helpful comments and encouragements, but also for their critical evaluation that helped me to interdisciplinary assess and improve the research work from various perspectives.

I also thank Professor Dr med. Michael Quintel, Professor Dr.med. José Hinz, Professor Dr. med. Onnen Mörer, PD Dr. med. Hassina Baraki, and PD Dr. med. Joachim Riggert, who gave me access to their facilities and provided me the opportunity to acquire the data and join their teams during the period of my internship. 